\title{
The Two Dimensions of Passion for Sport: A New Look Using a Quadripartite Approach
}

Benjamin J. I. Schellenberg ${ }^{1}$, Jérémie Verner-Filion ${ }^{2}$, Patrick Gaudreau ${ }^{3}$, and Sophia Mbabaali ${ }^{1}$

${ }^{1}$ Faculty of Kinesiology and Recreation Management, University of Manitoba

${ }^{2}$ Département des sciences de L’éducation, Université du Québec en Outaouais

${ }^{3}$ School of Psychology, University of Ottawa

\begin{abstract}
Author Note
Accepted author manuscript version reprinted, by permission, from the Journal of Sport \& Exercise Psychology, 2021 (ahead of print). (C) Human Kinetics, Inc.

Funding for this research was provided by the Social Sciences and Humanities Research Council of Canada (430-2018-00275) and by the University of Manitoba Research Grants Program. We thank Samantha Onchulenko and Alana Signore for their assistance with data collection.

Correspondence concerning this article should be addressed to Benjamin Schellenberg, Faculty of Kinesiology and Recreation Management, University of Manitoba, Winnipeg, MB, R3T 2N2. Email: ben.schellenberg@umanitoba.ca
\end{abstract}




\begin{abstract}
Research relying on the dualistic model of passion has consistently found that harmonious passion for sport is positively associated with adaptive outcomes and that obsessive passion for sport is positively associated with maladaptive outcomes (e.g., Vallerand \& Verner-Filion, 2020). In this research, we tested if various sport outcomes were related to within-person combinations of both harmonious and obsessive passion. Three samples of athletes (total $N=$ 1,290) completed online surveys that assessed various sport outcomes (e.g., sport enjoyment, goal attainment), along with harmonious and obsessive passion for their sport. We found that athletes were best served by having either high harmonious passion or low obsessive passion or, in many cases, high harmonious passion that was combined with low obsessive passion. These results add to our understanding of passion by showing that combinations of harmonious and obsessive passion for sport are differentially associated with indicators of a positive sport experience.
\end{abstract}

Keywords: dualistic model of passion; harmonious passion; obsessive passion; quadripartite approach 


\section{The Two Dimensions of Passion for Sport: A New Look Using a Quadripartite Approach}

"Passion first and everything will fall into place" - Holly Holm, mixed martial artist. Many endorse Holly Holm's stance and believe that "everything” in sport, such as success and well-being, can be achieved by having passion. This belief has been put to the test with empirical research (e.g., Curran et al., 2015; Vallerand \& Verner-Filion, 2020). This research has relied extensively on the dualistic model of passion (DMP; Vallerand, 2015), and has revealed that, to assess the effects of passion on athletes, it is critical to distinguish between two passion dimensions: harmonious passion (HP) and obsessive passion (OP). Over almost 20 years of research on the DMP, researchers have consistently shown that, although both HP and OP are positively associated with performance, HP predicts more adaptive outcomes (e.g., wellbeing) whereas OP does not predict adaptive outcomes and even predicts more maladaptive outcomes (e.g., negative emotions; see Schellenberg et al., 2020; Vallerand \& Verner-Filion, 2020).

Both theory and empirical research on the DMP, however, also suggest that athletes can simultaneously experience different degrees of both HP and OP (Curran et al., 2015; Vallerand, 2015). HP and OP for sport are not always mutually exclusive, and the DMP makes it clear that HP and OP operate on two continua and that both are present within individuals to different extents (Vallerand, 2015). For example, some athletes can experience high levels of both HP and OP, others can experience low levels of HP and OP, and others still can experience high levels of one dimension but low levels of the other. Although much is known about the unique effects of both HP and OP, little is known about how both passion dimensions combine to predict sport outcomes. For example, do athletes with high HP for sport have more positive experiences if they also have low OP? Does having high HP compensate for some of the negative effects that 
surface when OP is also high? Our objective was to address these types of questions and test associations between different combinations of HP and OP and sport outcomes among athletes.

\section{Passion for Sport}

According to the DMP, passion is defined as an intense desire to engage in an activity that one likes or even loves, values, pursues regularly, and has incorporated into one's identity (Vallerand, 2015). Importantly, the DMP conceptualizes passion as a dualistic construct involving both HP and OP dimensions. HP emerges when an activity is pursued in an autonomous way and involves a balanced, flexible engagement in an activity that remains under a person's control. OP emerges when an activity is pursued because of certain contingencies that are linked with it (e.g., a need for self-esteem), and involves a rigid, overzealous pursuit of an activity that often comes at the expense of other life domains. Therefore, although both HP and OP involve feeling love toward an activity and incorporating an activity into one's identity, they differ in the type of motivation that is felt toward an activity.

Thus far, research studying passion with athletes has relied almost exclusively on a unique effect approach that focuses on the relationship between outcomes and each passion dimension individually. From this approach, we have learned that HP and OP are most often predictive of adaptive and maladaptive sport outcomes, respectively (e.g., Gustafsson et al., 2011; Martin \& Horn, 2013; Stephan et al., 2009; Verner-Filion et al., 2017). It should be noted that some exceptions to this general pattern of results have been found. For example, OP has been associated with some adaptive outcomes such as greater performance in ego-threatening situations (Bélanger et al., 2013a), whereas HP has been associated with some maladaptive outcomes such as lower psychological adjustment within highly-competitive sport environments (Amiot et al., 2006). But overall, high HP is most often associated with adaptive sport outcomes, 
whereas high OP is most often associated with maladaptive sport outcomes (Vallerand \& Verner-Filion, 2020).

However, we have also learned that it may be critical to explore how both passion dimensions coexist within each individual. The DMP specifies that people feel different levels of both HP and OP toward an activity (Vallerand, 2015), and there are at least three arguments that can be made to support this point. First, HP and OP are almost always positively correlated with one another (Marsh et al., 2013). This means that many (but not all) people who have high (or low) levels of one passion dimension also experience correspondingly high (or low) levels of the other. Second, experimental research (e.g., Bélanger et al., 2013b) has shown that either HP or OP toward an activity can be temporarily enhanced using an experimental mindset-induction procedure. This means that either passion dimension has the potential to be temporarily activated within a person by different situational or environmental forces. Third, activity internalization the key process that shapes the development of both HP and OP (Mageau et al., 2009) - is complex and is sensitive to forces at global (e.g., personality characteristics), contextual (e.g., features of the activity environment), and situational levels (e.g., day-to-day variations; Vallerand, 1997). For example, athletes approach sport with their own tendencies to internalize activities in either a more autonomous or controlled way (e.g., Chan \& Hagger, 2012). But athletes also experience different sport phases (e.g., tryouts, pre-season, playoffs), contexts (e.g., practices, competitions, fitness training) and other environmental features (e.g., autonomy support from others, rewards, punishments) that can each promote autonomous or controlled activity internalization to different degrees (Vallerand, 1997). This means that activities are often internalized in a way that can facilitate different degrees of both HP and OP. For these reasons, there have been calls for passion researchers to start focusing on the effects of different within- 
person combinations of both HP and OP (Curran et al., 2015; Vallerand \& Verner-Filion, 2020).

In this research, we attempted to answer these calls by relying on the recently developed quadripartite approach to passion (Schellenberg et al., 2019).

\section{Quadripartite Approach to Passion}

The quadripartite approach to passion (Schellenberg et al., 2019) was recently introduced as an extension of the DMP to test associations between different within-person combinations of HP and OP and outcomes. Like similar approaches to other dualistic constructs such as perfectionism (e.g., Gaudreau, 2012), the quadripartite approach to passion distinguishes between four passion subtypes based on high and low levels of HP and OP: pure HP (high HP combined with low OP), pure OP (high OP combined with low HP), mixed passion (high HP combined with high OP), and non-passion (low HP combined with low OP). ${ }^{1}$ For example, some athletes may feel only highly harmoniously passionate about their sport (representing pure HP), others who feel only highly obsessively passionate toward their sport (representing pure OP), others still who feel highly harmonious toward their sport and also highly obsessed (representing mixed passion), and finally those who play a sport but do not feel that this is a passion for them (representing non-passion).

Schellenberg and colleagues (2019) acknowledge that, of these four passion subtypes, mixed passion is perhaps the most complex and warrants additional elaboration. With mixed passion, people feel that their passionate activity is a highly harmonious part of their lives, but also that it can become highly obsessive. For example, athletes with mixed passion may reflect on their sport and feel that they are generally in control of their sport participation and that it is

\footnotetext{
${ }^{1}$ This final subtype has been referred to as both non-passion (Schellenberg et al., 2019) and low passion (Schellenberg et al., 2021). Although both labels seem suitable, here we have opted for the term non-passion in order to be consistent with Schellenberg et al. (2019) and because we did not restrict participants to those who surpassed a certain threshold on passion quantity (see Schellenberg et al., 2021).
} 
well-integrated into their lives. They would therefore feel high levels of HP. But these athletes may also feel that their engagement in sport can at times get out of control and can become overwhelming. There may be certain phases of a season (e.g., playoffs), goals (e.g., learning a new skill/routine), or contexts (e.g., professional athletes playing in a "contract year") that could foster a more controlled internalization and thus promote high levels of OP toward sport. Therefore, when athletes reflect on their overall feelings toward their sport, the quadripartite approach assumes that athletes can report high levels of both HP and OP.

In outlining this new approach, Schellenberg and colleagues (2019) proposed six hypotheses regarding which passion subtypes would predict more adaptive outcomes than others. These hypotheses were based on the findings that have emerged in research relying on the DMP using a unique effects approach (Curran et al., 2015; Vallerand, 2015). The first three hypotheses predict that pure HP will be associated with more adaptive outcomes than pure OP (Hypothesis 1), mixed passion (Hypothesis 2), and non-passion (Hypothesis 3). Hypothesis 4 predicts that mixed passion will be associated with more adaptive outcomes than pure OP. Finally, given limited empirical evidence and theoretical arguments that can be made in support of opposing hypotheses (Schellenberg et al., 2019), the final two hypotheses present competing hypotheses specifying that the non-passion subtype will be associated with worse (Hypothesis 5a) or better (Hypothesis 5b) adjustment than pure OP, and worse (Hypothesis 6a) or better (Hypothesis 6b) adjustment than mixed passion.

Initial research by Schellenberg and colleagues (2019) studying physical and psychological health outcomes among undergraduates and video gamers found support for Hypotheses 1-4 and 5b, no support for Hypothesis 5a, and inconsistent support for either Hypotheses $6 \mathrm{a}$ or $6 \mathrm{~b}$. The quadripartite approach has since been used to assess differences in 
perceptions of self-compassion among students (Schellenberg et al., 2021), and to assess

differences in marijuana-related consequences among marijuana users (Dolan et al., 2021). These studies found that having high OP (i.e., either pure OP or mixed passion), especially when combined with low HP (i.e., pure OP), is associated with less optimal outcomes including less adaptive beliefs about engaging in self-compassion and more cravings for and negative consequences derived from marijuana use. Research has yet to study outcomes among athletes using the quadripartite approach.

\section{The Current Research}

The purpose of this research was to test the six hypotheses of the quadripartite approach with athletes. There is reason to expect that the quadripartite approach would be especially important in sport. Sport is a domain in which athletes are often highly passionate (Vallerand \& Verner-Filion, 2020) but that also involves forces that can promote both HP (e.g., autonomysupport from others) and OP (e.g., performance pressure, controlling behaviors of others; see Mageau et al., 2009). This means that athletes likely experience both HP and OP to varying degrees. But it is currently not known if athlete outcomes are associated with specific combinations of HP and OP. As an example, to avoid feeling stressed in sport, is it best for athletes to have high HP (regardless of their level of OP), low OP (regardless of their level of HP), or high HP that is combined with low OP? The quadripartite approach allows questions such as this to be addressed. Therefore, we reason that studying passion with a quadripartite approach is especially useful in the sport context.

Both HP and OP have been linked with a broad range of outcomes in athletes (Vallerand \& Verner-Filion, 2020). We therefore aimed to assess a variety of outcomes in the current research in order to provide a wide-ranging first test of the six hypotheses of the quadripartite 
approach among athletes. The outcome variables that we assessed included experiences of enjoyment, satisfaction with life, stress, worry, flow, psychological well-being, positive and negative feelings, goal attainment, injury experiences, psychological need satisfaction, group cohesion, moral disengagement, sportspersonship, relationship quality with teammates, and psychological need thwarting. These variables were selected because they represent an assortment of different cognitive (e.g., flow), affective (e.g., positive affect), motivational (e.g., need satisfaction), interpersonal (e.g., relationship quality), and behavioral (e.g., injury experiences) variables that have been researched extensively in sport psychology. They also included outcomes that were both positively (e.g., sport enjoyment) and negatively laden (e.g., stress), and both sport-specific (e.g., worry) and global (e.g., satisfaction with life) in nature. Because we were interested in many athlete outcomes, we divided our assessments across three samples of athletes to reduce participant burden. Samples 1 and 2 each focused on various sport outcomes, whereas Sample 3 focused mainly on interpersonal outcomes related to team sport settings (e.g., group cohesion, relationships with teammates). Institutional ethics approval was obtained prior to data collection, and each participant provided informed consent. Anonymous data and syntax files for each sample are available on the Open Science Framework at https://osf.io/c6sz5/.

\section{Method}

\section{Participants}

Participants in each sample were primarily recruited from Prolific Academic (www.prolific.co). Prolific is an online recruitment website that allows users to complete online surveys in exchange for monetary payment (Palan \& Schitter, 2018). Research has shown that Prolific can allow researchers to collect high-quality data from diverse samples of participants 
(Peer et al., 2017). To detect dishonest responding in this research, all participants were asked at the end of each online survey to indicate if they responded honestly to the survey questions by typing either "yes" or "no" in a text box. Participants who reported dishonestly responding (see data exclusions below) were removed from the analyses.

Prolific users complete a screening survey upon initial registration with Prolific Academic, and to be invited to participate in this research they must have reported on the survey that they were (a) 18 years of age or older, and (b) played a sport on a regular basis. ${ }^{2}$ In addition, participants were only allowed to complete one of the three surveys that were posted on Prolific. All participants responded to survey questions while thinking of a sport they were currently playing. We based our targeted sample size on the number of participants required for structural equation models (SEMs), the approach that we used for hypothesis testing. Required sample sizes for SEMs can vary depending on many unknown factors, such as the magnitude of item loadings, factor correlations, and the amount of missing data (Kline, 2016). We aimed to recruit at least 300 participants for each sample because we reasoned that this was a feasible goal that would result in samples sizes that were typical in SEM analyses and that were comparable to previous research adopting the quadripartite approach with latent variables (Schellenberg et al., 2019). Specific details about the participants in each sample are as follows:

Sample $1(N=\mathbf{4 4 2})$. All participants in Sample 1 were Prolific users. An additional 22 participants completed this study, but they were excluded because they reported that they were not currently playing a sport. Participants (250 males, 185 females, 2 non-binary participants, 5 participants did not report a gender) ranged from 18 to 73 years old $(M=34.65$ years, $S D=$

\footnotetext{
${ }^{2}$ Although we refer to participants in this research as "athletes", we acknowledge that they may not satisfy some of the criteria that have been proposed to be considered an athlete (e.g., being formally registered with a sport federation; see Araújo \& Scharhag, 2016).
} 
11.33 years), and most identified having a White/European ethnic background (83.5\%).

Participants reported spending an average of 4.40 hours $(S D=3.30$ hours $)$ per week participating in their sport. Participants were compensated with $£ 1.14$ (approximately \$1.48 USD).

Sample $2(N=499)$. Participants in Sample 2 were athletes recruited from either Prolific Academic $(N=442)$ or from undergraduate kinesiology classes $(N=57)$. An additional 11 participants completed this study, but they were excluded because they either reported that they were not currently playing a sport $(n=7)$ or because they were not honest in their responses $(n=$ 4). Participants (270 males, 224 females, 5 participants did not report a gender) ranged from 18 to 69 years old $(M=33.65$ years, $S D=11.74$ years $)$, and most identified having a White/European ethnic background (85.0\%). Participants reported spending an average of 5.13 hours $(S D=4.10$ hours $)$ per week participating in their sport, and most $(63.9 \%)$ considered their sport to be at least moderately competitive. Participants were compensated with either electronic gift cards (undergraduates) or $£ 2.89$ (Prolific users, approximately $\$ 3.78 \mathrm{USD}$ ). ${ }^{3}$

Sample $3(N=349)$. All participants in Sample 3 were Prolific users. In addition to the criteria listed above, users were invited to participate if they reported on the Prolific screening survey that they played a team sport on a regular basis (e.g., rugby, basketball). This additional criterion was specified because participants in this sample answered questions assessing interpersonal outcomes in sport. A total of 510 participants completed this study, but we excluded 161 participants from the analyses because they either indicated on the survey that they played a sport that we did not consider to be a team sport (e.g., boxing, running; $n=158$ ), reported on an integrity-check item that they were not honest in their responses $(n=2)$, or

\footnotetext{
${ }^{3}$ The data collected from Sample 2 are also being used for a separate project that we are currently preparing for publication. The current research focuses on different variables and tests different hypotheses than this other project.
} 
reported that they did not play their sport on a regular basis $(n=1) .^{4}$ Therefore, the analysis was based on a sample of 349 athletes. Participants (191 males, 153 females, 1 non-binary participant, 4 participants did not report a gender) ranged from 18 to 71 years old $(M=34.86$ years, $S D=10.29$ years), and most identified having a White/European ethnic background (80.5\%). Participants reported spending an average of 4.54 hours $(S D=4.26$ hours) per week participating in their sport, and most $(70.80 \%)$ considered their sport to be at least moderately competitive. Participants were compensated with $£ 2.89$ (approximately \$3.78 USD). ${ }^{5}$

\section{Measures}

Harmonious and obsessive passion (Samples 1, 2, and 3). Athletes answered questions from the Passion Scale (Marsh et al., 2013; Vallerand, 2015) to assess levels of HP (6 items; e.g., "My sport is well integrated in my life") and OP (6 items; e.g., "I have almost an obsessive feeling for my sport") for their sport. Participants answered each item on a 7-point scale ranging from 1 (not agree at all) to 7 (totally agree). The Passion Scale has been extensively used in sport (see Vallerand \& Verner-Filion, 2020) and has received strong psychometric support (e.g., Marsh et al., 2013; Vallerand, 2015).

Enjoyment (Sample 1). Enjoyment in sport was assessed with four items that have been used in previous research on the Sport Commitment Model (e.g., Scanlan et al., 1993). Each item (e.g., "Do you enjoy playing your sport") was assessed on a 5-point scale ranging from 1 (not at all) to 5 (very much). Initial research has supported the face validity and factor structure of this scale in sport participants (Scanlan et al., 1993).

\footnotetext{
${ }^{4}$ Although all participants reported playing a team sport on the Prolific screening survey, they were able to answer the survey items for this research while thinking of any sport that they played, including a non-team sport. This is why we were required to exclude a large proportion of participants from our analysis.

${ }^{5}$ Data collection for each sample was completed on January 31, 2020, prior to restrictions related to the COVID-19 pandemic that may have affected sport participation.
} 
Satisfaction with life (Sample 1). Overall life satisfaction was assessed with the 5-item Satisfaction with Life Scale (SWLS; Diener et al. 1985). Participants rated their agreement with statements about their overall satisfaction with life (e.g., "In most ways my life is close to my ideal") on a 5-point scale ranging from 1 (strongly disagree) to 5 (strongly agree). The SWLS is a very popular scale that has received strong psychometric support (see Pavot \& Diener, 2008).

Stress (Sample 1). Stress in sport was assessed with a single-item stress thermometer (e.g., Kowalski \& Crocker, 2001). Participants were presented with a horizontal sliding scale that ranged from 0 (no stress at all) to 100 (intolerable stress) and asked to indicate the amount of stress that they typically experience playing their sport $(M=26.22, S D=21.67)$. The stress thermometer is a common way of assessing stress appraisals in sport (e.g., Britton et al., 2019).

Worry (Sample 1). Worrying in sport was assessed with the 5-item worry subscale of the Sport Anxiety Scale-2 (Smith et al., 2006). Participants were asked to indicate how they usually feel before or while they played their sport (e.g., "I worry that I will not play well") on a 4-point scale ranging from 1 (not at all) to 4 (very much). Initial research has supported the psychometric properties of this scale (Smith et al., 2006).

Flow (Sample 2). The extent to which athletes experience flow while playing sport was assessed with the CORE Flow State Scale (C-FSS; Jackson et al., 2010). This C-FSS assess the core experience of being in flow with 10 items (e.g., I am 'totally involved') on a 5-point scale ranging from 1 (never) to 5 (always). Participants were asked to answer the questions while thinking of their general feelings and experiences in their sport. Jackson et al. (2010) review evidence supporting the validity and reliability of C-FSS scores.

Well-being (Sample 2). Participants completed the recently-developed Sport Mental Health Continuum - Short Form (Foster \& Chow, 2019; Sport MHC-SF) as a sport-specific 
measure of well-being. The Sport MHC-SF is adapted from the MHC-SF (Keyes et al., 2008) to measure three components of well-being in sport: subjective well-being (e.g., "...happy”), psychological well-being (e.g., “...that you liked most parts of your athletic personality”), and social well-being (e.g., “...that you belong to your team or sport community”). Participants reported how often in the past month their sport participation made them feel certain ways using a 6-point scale from 0 (never) to 5 (always). The MHC-SF is a newer scale but showed acceptable psychometric properties as part of its initial development (Foster \& Chow, 2019).

Positive and negative feelings (Sample 2). Positive and negative feelings in sport were assessed with the Scale of Positive and Negative Experience (SPANE; Diener et al., 2010). The SPANE assessed both positive (6 items; e.g., "Pleasant") and negative (6 items; e.g., "Afraid”) feelings using a 5-point scale ranging from 1 (very rarely or never) to 5 (very often or always). Participants were asked to report the extent to which they had experienced certain feelings over the past 4 weeks while playing their sport. Previous research has supported the psychometric properties of the SPANE (e.g., Jonanovic, 2015).

Goal attainment (Sample 2). The extent to which participants were achieving their goals in sport was assessed with the Sport Achievement Goal Scale (A-SAGS; Gaudreau et al., 2002, as cited in Gaudreau \& Blondin, 2004). The A-SAGS assessed the extent to which three types of approach-oriented goals have been attained: mastery goals (4 items; e.g., "I have been executing my movements correctly"), self-improvement (4 items; e.g., "I have been doing better than my usual performances"), and performance goals (4 items; e.g., "I have been showing that I am superior to other athletes"). Participants responded to each item using a 7-point scale ranging from 1 (not agree at all) to 7 (totally agree) while thinking of their experiences over the past 4 
weeks playing their sport. Previous research has supported the factor structure of the A-SAGS (see Gaudreau \& Blondin, 2004).

Injury experiences (Sample 2). Participants answered two questions regarding their injury experiences in sport. First, participants reported how many injuries they experienced over the past 12 months as a result of playing their sport. They were instructed to only include injuries that required medical attention or withdrawal from sport for one day or more $(M=0.84, S D=$ 1.33). Next, on a 7-point scale ranging from 1 (not agree at all) to 7 (totally agree), participants rated their agreement with the following statement: "I will be injured at one point during the next 12 months as a result of playing my sport" $(M=2.82, S D=1.76)$. Both questions were intended to be brief, face-valid assessments of injury experiences in sport.

Psychological need satisfaction (Sample 3). Athletes’ psychological need satisfaction was measured using three scales that have been used in previous research conducted within sport and that have shown favorable psychometric properties (e.g., Bartholomew et al., 2011; Standage et al., 2003, 2005). Need for relatedness was assessed using the 5-item acceptance subscale from the Need for Relatedness Scale (NRS-10; Richer \& Vallerand, 1998; e.g., "In my relationship with my teammates, I feel listened to"). Need for competence was assessed with the 5-item perceived competence subscale from the Intrinsic Motivation Inventory (IMI; McAuley et al., 1989; e.g., "I am satisfied with my performance in my sport”). Need for autonomy was assessed using 5-items from Standage et al. (2003; e.g., "In my sport, I have a say regarding what skills I want to practice"). Participants answered all items on a 7-point scale ranging from 1 (not agree at all) to 7 (totally agree).

Group cohesion (Sample 3). Group cohesion was measured using the Group Environment Questionnaire (GEQ; Carron et al., 1985). The 18-item GEQ assesses individual 
attractions to the group-social (5 items; e.g., "Some of my best friends are on this team"), individual attractions to the group-task (4 items, all reversed scored; e.g., "I'm unhappy with my team's level of desire to win"), group integration-social (4 items; e.g., "Our team would like to spend time together in the off season"), and group integration-task (5 items; e.g., "Our team is united in trying to reach its goals for performance"). Participants answered each item on a 9point scale ranging from 1 (strongly disagree) to 9 (strongly agree). The GEQ is a widely used scale in sport that has demonstrated favorable psychometric properties (e.g., Li \& Harmer, 1996).

Moral disengagement (Sample 3). The 8-item Moral Disengagement in Sport ScaleShort (MDSS-S; Boardley \& Kavussanu, 2008) was used to assess moral disengagement in athletes. Each item corresponds to one of eight mechanisms of moral disengagement (e.g., "Bending the rules is a way of evening things up"). Participants answered each item on a 7-point scale ranging from 1 (strongly disagree) to 7 (strongly agree). Boardley and Kavussanu (2008) report evidence in support of the validity and reliability of scores obtained from the MDSS-S.

Sportspersonship (Sample 3). The Multidimensional Sportspersonship Scale (MSOS25; Vallerand et al., 1997) was used to measure athletes' sportspersonship. The 25-item questionnaire consists of five 5-item subscales assessing athletes' respect for social conventions (e.g., "Win or lose, I shake hands with the opponent after the game"), respect for the rules and the officials (e.g., "I respect the rules"), respect for one's full commitment toward sport participation (e.g., "I don't give up even after making many mistakes"), respect and concern for the opponent (e.g., "I help the opponent get up after a fall"), and negative approach toward the practice of sport (e.g., "I compete for personal honors, trophies, and medals"). Participants answered each item on a 5-point scale ranging form 1 (not like me at all) to 5 (exactly like me). Vallerand et al. (1997) report adequate reliability and validity of MSOS-25 scores with athletes. 
Teammate relationship quality (Sample 3). The Quality of Interpersonal Relationships Scale (QIRS; Senécal et al., 1992) was used to measure the quality of participants' relationships with their teammates using four items (e.g., "At the moment, my relationships with my teammates are satisfying"). Participants answered each item on a 5-point scale ranging from 0 (not at all) to 4 (extremely). The QIRS has been used in previous research examining relationship quality among athletes (e.g., Philippe et al., 2010).

Psychological need thwarting (Sample 3). Athletes responded to the Psychological Need Thwarting Scale (PNTS; Bartholomew et al., 2011) to measure basic psychological need thwarting of relatedness (e.g., "I feel others can be dismissive of me"), competence (e.g., "There are situations where I am made to feel inadequate") and autonomy (e.g., "I feel pushed to behave in certain ways"), each with four items. Participants answered each item on a 7-point scale ranging from 1 (strongly disagree) to 7 (strongly agree). Evidence has been obtained in support of the reliability and validity of PNTS scores (see Bartholomew et al., 2011).

\section{Data Analysis}

We conducted preliminary analyses in SPSS to calculate descriptive statistics and check for missing data. Descriptive statistics and a scatterplot of the relationship between HP and OP are reported in the Supplementary Material (Table S1-S3 and Figure S1, available online). There were very little missing data in each sample (each sample: $\leq 0.03 \%$ missing); this is likely because participants were prompted, but not required, to answer unanswered questions at the end of each survey page. Missing data were therefore managed using full information maximum likelihood, the default option in Mplus (version 8.4).

We tested the six hypotheses of the quadripartite approach in Mplus using latent moderation SEM. This approach allowed us to capitalize on the advantages of analyzing latent 
variables compared to manifest variables, including the control of measurement error (e.g., Cole \& Maxwell, 2003). All models were estimated using robust full information maximum likelihood (MLR) to account for potential deviations in normality.

We analyzed the data in three steps, using the same procedures described by Schellenberg et al. (2019). First, we conducted confirmatory factor analyses (CFAs) with each scale individually, with each outcome variable along with HP and OP, and with all variables simultaneously (see Table S4). These CFA models allowed us to test the fit of each scale, identify potential sources of misfit, and make model modifications if needed. Second, we tested interactive effects models in which each outcome variable was regressed on latent variables representing HP and OP (both mean centered) and their interaction effect. We also tested main effects models in which each outcome variable was regressed on latent variables representing HP and OP (both mean centered), and the interaction effects were constrained to zero. In situations in which an interaction effect was not statistically significant, main effects models were interpreted as a way to enhance model parsimony and to ensure that the effect of both HP and OP were not conditioned on the mean value of a non-significant interaction term (Gaudreau, 2012).

Finally, we tested each hypothesis by estimating the predicted values of outcome variables for each passion subtype and testing the differences between them by estimating simple intercepts and simple slopes at high and low levels of each passion dimension (see Gaudreau, 2012; Schellenberg et al., 2019). High and low levels were plotted at one standard deviation above and below the mean, respectively. Interpreting simple slopes allows differences between four passion subtypes to be tested: Mixed passion vs. pure HP (Hypothesis 2; simple slope: OP at high HP), pure HP vs. non-passion (Hypothesis 3; simple slope: HP at low OP), mixed passion vs. pure OP (Hypothesis 4; simple slope: HP at High OP), and pure OP vs. non-passion 
(Hypothesis 5; simple slope: OP at low HP). When an interaction effect was not statistically significant, main effects models were interpreted and the main effects were used to calculate the predicted values of each of the four subtypes (Gaudreau, 2012). Differences between pure HP and pure OP (Hypothesis 1) and between mixed passion and non-passion (Hypothesis 6) cannot be compared using simple slopes; therefore, they were compared by computing Cohen's $d$ values and interpreting the corresponding significance tests. Cohen's $d$ values were computed by dividing the difference between both predicted values by the standard deviation of the outcome variable (Gaudreau et al., 2016). All standard deviations were calculated using the square root of the variance obtained in CFAs that included HP, OP, and the outcome variable. ${ }^{6}$

\section{Results}

\section{CFAs}

The Supplementary Material (available online) reports complete details regarding the modelling of latent variables and the fit indices for the CFAs with each subscale individually, each subscale along with both HP and OP, and all variables assessed in each sample (Tables S4S6). Here we would like to briefly note several modifications that were made to individual scales in order to achieve acceptable fit, including adding three sets of correlated residuals with the HP subscale, one correlated residual with the autonomy scale, one correlated residual and excluding two items from the moral disengagement scale, and excluding items that assessed a negative approach toward the practice of sport from the measure of sportspersonship. After necessary modifications were made, acceptable fit indices were obtained with all CFAs.

\section{Hypothesis Testing}

\footnotetext{
${ }^{6}$ We also checked for the influence of outliers. First, we identified potential outliers by visually inspecting Mahalanobis distance scores obtained from the CFAs in Mplus. Second, we repeated all analyses with potential outliers excluded (each analysis excluded between 0 and 7 outliers). Removing potential outlying cases did not affect the results in any substantial way. We therefore report analyses that include all cases.
} 
Results from interactive and main effects models for each outcome variable in each sample are reported in Table 1. Hypothesis tests are reported in Table 2, and passion subtypes are plotted in Figure 1. A summary of the hypotheses and those that were and were not supported is reported in Table 3.

Hypothesis 1. With 23 of the 25 outcome variables, support for Hypothesis 1 was obtained by finding that pure HP was associated with better outcomes than pure OP. The two exceptions were with performance goal attainment and injury history, which showed no difference between the two subtypes.

Hypothesis 2. With 15 of the 25 outcomes, support for Hypothesis 2 was obtained by finding that pure HP was associated with better outcomes than mixed passion. There were no differences between these two subtypes in all other cases except for performance goals, in which mixed passion was associated with greater attainment of performance goals than pure HP.

Hypothesis 3. With 20 of the 25 outcomes, support for Hypothesis 3 was obtained by finding that pure HP was associated with better outcomes than non-passion. There were no differences between these two subtypes in all other cases.

Hypothesis 4. With 20 of the 25 outcomes, support for Hypothesis 4 was obtained by finding that mixed passion was associated with better outcomes than pure OP. There were no differences between these two subtypes in all other cases.

Hypothesis 5. With 15 of the 25 outcomes, support for Hypothesis 5 b was obtained by finding that non-passion was associated with better outcomes than pure OP. Support for Hypothesis 5a was obtained only with performance goals, whereby pure OP was associated with greater attainment of performance goals than non-passion. The nine other cases did not support either Hypotheses $5 \mathrm{a}$ or $5 \mathrm{~b}$. 
Hypothesis 6. With 16 of the 25 outcomes, support for Hypothesis 6 a was obtained by finding that mixed passion was associated with better outcomes than non-passion. Support for Hypothesis $6 \mathrm{~b}$ was obtained 8 outcomes, which each showed that non-passion was associated with better outcomes than non-passion. Only with relatedness need thwarting was support for either hypothesis not obtained. ${ }^{7}$

\section{Discussion}

Research relying on the DMP has repeatedly found value in distinguishing between harmonious and obsessive dimensions of passion for predicting outcomes among athletes (Vallerand \& Verner-Filion, 2020). Our aim was to contribute to this literature and test the associations between sport outcomes and different within-person combinations of HP and OP. Of the 25 outcomes that we assessed, we found that pure HP was associated with more adaptive outcomes than mixed passion, non-passion, and pure OP on 10 outcomes. We also found that mixed passion was associated with better outcomes than both non-passion and pure OP on 16 outcomes. In fact, of these 16 outcomes, mixed passion did not differ from pure HP on 9 outcomes, and was associated with higher levels of performance goal attainment. Finally, pure OP was associated with less adaptive outcomes than all other passion types, including nonpassion, on 10 outcomes. Overall, this study demonstrates how using a quadripartite approach can reveal the effects of having high/low combinations of HP/OP among athletes.

\section{The Quadripartite Approach to Sport Passion}

\footnotetext{
${ }^{7}$ Additional exploratory analyses revealed that the positive association between OP and moral disengagement was moderated by gender. Follow-up analyses indicated that the effects we observed were statistically significant for male participants only. More details of this analysis are provided in the Supplementary Material. We did not hypothesize this moderation effect, gender effects are typically not reported in the passion literature, and gender did not moderate any of the other effects in this research. We therefore believe this finding warrants additional study before drawing any conclusions.
} 
The main takeaway from our findings is that athletes are best served by having either high HP (i.e., either pure HP or mixed passion) or low OP (i.e., either pure HP or non-passion) or, in many cases, high HP combined with low OP (i.e., pure HP). This conclusion can be reached by focusing on either the main or the interactive effects of HP and OP on each outcome in order to test the six hypotheses set forth by the quadripartite approach. Results of the main and interactive models revealed that, of the 25 outcomes that we assessed, both HP and OP mattered when testing associations with 12 of them: satisfaction with life, negative affect, positive affect, flow, performance goal attainment, relatedness and autonomy need satisfaction, team cohesion, relatedness, competence, and autonomy need thwarting, and sportspersonship. This was shown statistically by the presence of either main effects of both HP and OP, or a statistical interaction between the two. It can also be seen visually in Figure 1 by the presence of either parallel simple slopes that are both non-horizontal (indicating a main effect of HP) and do not overlap with one another (indicating a main effect of OP), or by the presence of simple slopes that are not parallel (indicating an HP $\times$ OP interaction effect). The results largely support one or both of the following conclusions: (a) adaptive sport outcomes are most often experienced by athletes with high HP combined with low OP (i.e., pure HP), and (b) maladaptive sport outcomes are most often experienced by athletes with high OP combined with low HP (i.e., pure OP).

For the 13 other outcomes that were assessed, all that mattered was the presence or absence of either HP or OP. With 8 outcomes (enjoyment, subjective, social, and psychological well-being, mastery and improvement goal attainment, competence, and relationship quality), all that mattered were levels of HP. This was shown statistically by the presence of a main effect of HP only, and visually in Figure 1 by the presence of parallel simple slopes that are both nonhorizontal (indicating a main effect of HP) but nearly overlap with one another (indicating no 
main effect of OP). The results with these outcomes support the conclusion that, to derive adaptive outcomes from having passion for sport, all that matters is that one's passion is characterized by high HP. With 5 other outcomes (stress, worry, injury history, injury likelihood, and moral disengagement), all that mattered were levels of OP. This was shown statistically by the presence of a main effect of OP only, and visually in Figure 1 by the presence of parallel simple slopes that are both nearly horizontal (indicating no main effect of HP) but do not overlap with one another (indicating a main effect of OP). The results with these outcomes support the conclusion that, to derive adaptive outcomes from having passion for sport, all that matters is that one's passion is characterized by low OP.

The tests of the six hypotheses of the quadripartite approach also showed the value of pursuing sport with high levels of HP and/or low levels of OP. In 10 of the 25 outcomes that we assessed, pure HP was associated with more adaptive outcomes than pure OP (Hypothesis 1), mixed passion (Hypothesis 2), and non-passion (Hypothesis 3). Based on our current understanding of both HP and OP (Curran et al., 2015; Vallerand, 2015), pure HP should be associated with better adjustment than other passion subtypes given that it involves all the hallmarks of HP (e.g., activity control, positive emotions, mindfulness) without any of the costs connected with OP (e.g., activity conflict, rumination; see Schellenberg et al., 2019). Our results support this hypothesis with most of the outcomes that we assessed. We also found support for Hypothesis 4, which predicts that mixed passion is associated with better outcomes than pure OP. This finding supports the view that having high HP can protect against or compensate for the costs that come when high levels of OP are also present (Schellenberg \& Bailis, 2015).

Hypothesis 5 compares pure OP with non-passion, and therefore addresses the provoking question of whether it is better to have a passion that is characterized by pure OP, or to have no 
passion at all. The results were most supportive of Hypothesis $5 \mathrm{~b}$, which predicts that nonpassion is associated with better outcomes than pure OP, although no differences were found with 9 outcomes and evidence in support of the opposite conclusion was found with one outcome (performance goals). But on balance, and when considering these results with research conducted outside of sport (Dolan et al., 2021; Schellenberg et al., 2019), it is clear that Hypothesis 5b has emerged as the hypothesis with more support than Hypothesis 5a; in most cases, the costs associated with pure OP outweigh any costs that come from pursuing an activity with no passion. This finding contradicts the belief expressed in the Holly Holm quote that began this article; it is often better to have no passion for sport compared to having passion that is purely obsessive.

Hypothesis 6, which presents two competing hypotheses predicting that mixed passion is associated with better (Hypothesis 6a) or worse (Hypothesis 6b) outcomes than non-passion, showed mixed support for each: Hypothesis 6a was supported with 16 outcomes, Hypothesis $6 \mathrm{~b}$ was supported with 8 outcomes, and no support for either hypothesis was found with 1 outcome (relatedness need thwarting). Looking closer at the outcomes supportive of each hypothesis shows that the outcomes supportive of Hypothesis 6a were all positively-laden (e.g., enjoyment, satisfaction with life), whereas the outcomes supportive of Hypothesis 6b were all negativelyladen (e.g., stress, worry). This means that, compared with non-passion, mixed passion is linked with more of both adaptive and maladaptive outcomes. By involving high levels of both HP and OP, mixed passion among athletes appears to involve experiences known to be associated with both (e.g., Curran et al., 2015). However, more support was found for Hypothesis 6a, which again supports the idea that, when both HP and OP are high, having high HP can often compensate for the drawbacks linked with high OP. 
One potential exception to the general conclusion that HP is adaptive and OP is maladaptive was with performance goal attainment, which was positively associated with both HP and OP. The highest levels of performance goal attainment were associated with mixed passion, the lowest levels of performance goals were associated with non-passion, and pure HP and pure OP did not differ from one another. An explanation for this finding is that athletes whose passion is characterized by mixed passion are indeed better able to outperform others and thus attain performance goals. A consistent result in the passion literature is that both HP and OP predict processes that facilitate performance, such as engaging in deliberate practice (e.g., Vallerand et al., 2007; Verner-Filion et al., 2017). Having high levels of OP might be especially conducive to performance goal attainment given that it entails an ego-invested and contingent mode of functioning (Vallerand, 2015), which could enhance one's desire to outperform others. Therefore, having high HP and OP could indeed be the best recipe for attaining performance goals. Another explanation is that our classification of performance goal attainment as an adaptive outcome was mistaken in the first place. Our assessment in this study focused on approach forms (e.g., outperforming others) rather than avoidance forms (i.e., avoiding performing worse than others) of performance goal attainment. Although pursuing performanceapproach goals has been linked with better performance, it has been suggested that pursuing performance-approach goals over-emphasizes social comparison, especially in contexts such as sport in which comparison with others is salient and public, and relate to maladaptive outcomes such as anxiety, dissatisfaction, and unethical behavior (Van Yperen et al., 2014). Therefore, the successful pursuit of performance goals could be viewed as not being entirely adaptive.

There were other outcome variables with which some hypotheses were not supported (see Table 3). Although we are reluctant to interpret these null effects too extensively, they may 
nevertheless reveal more about how both HP and OP function in sport. For example, HP was positively associated with flow, but was unrelated to experiences of stress and worry. This may mean that athletes with high HP experience adaptive cognitive process in some ways (i.e., getting "in the zone") but not in others (i.e., avoiding stress and worry about performances). Also, despite the many maladaptive outcomes linked with OP (e.g., negative affect, injury perceptions, stress), it was not related with any component of athlete well-being. This may mean that any negative impact of these maladaptive outcomes on well-being could be offset by other more adaptive outcomes that have been positively associated with OP (e.g., high performance and psychological adjustment in ego-threatening and highly-competitive contexts; see Amiot et al., 2006; Bélanger et al., 2013a). The only way to understand more about the null effects observed in this research is with additional research adopting the quadripartite approach.

\section{Limitation and Future Directions}

The conclusions of this research are limited by the use of self-report assessments and by samples that were recruited almost exclusively from the Prolific Academic crowdsourcing platform. It is also important to emphasize that the cross-sectional design of this research does not allow for any causal conclusions to be made. More research is needed with different research designs (e.g., longitudinal, experimental), samples of sport participants (e.g., highly-competitive athletes, coaches), and sampling methods (e.g., in-person recruitment) to advance our understanding of the different outcomes that are linked with passion subtypes in sport. We should also note that, as part of the CFA analysis, some scale modifications were made, including items being excluded from assessments of moral disengagement and sportspersonship. Modifications such as these limit the conclusions that can be made about these outcomes and necessitate additional research. 
We believe that the quadripartite approach to the study of passion in sport is a valuable approach that can complement findings derived from a unique effects approach. We have two main reasons for this viewpoint. First, as this research has shown, combinations of HP and OP matter for testing associations with sport outcomes. Evidence for this can be found by interpreting either main or interactive effects and testing differences between prototypical passion subtypes. There is also evidence that athletes do indeed report differing degrees of both HP and OP for their sport. For example, the Supplementary Material (available online) reports that HP and OP were positively correlated within each sample, and displays a scatterplot (Figure S1) that shows that athletes report varying degrees of both HP and OP. Second, we believe the quadripartite approach opens the door for many interesting questions about the interplay between HP and OP. For instance, does having high HP protect against the costs that often come when OP is also high? To be happy and healthy in sport, is it better to have a pure OP, or to have no passion at all? The current research addressed these two questions, but there are many others that can be the focus of future research adopting the quadripartite approach, including those related to mediation (e.g., "Why is pure HP often associated with more adaptive outcomes than other passion subtypes") or moderation (e.g., "Are there times when or environments in which it is most adaptive to have a pure OP?"). There are also other sport outcomes that can be measured and tested in relation to HP and OP. We tried to measure a variety of outcomes in this research that were important in sport and that have been studied extensively in sport psychology. However, many important outcomes were not included and need to be studied in future research, perhaps most notably sport performance.

\section{Conclusion}


How can athletes experience "everything" in sport, including high well-being and goal attainment? To date, research has shown that athletes can experience adaptive outcomes by pursuing their sport with either high levels of HP or low levels of OP (Vallerand \& VernerFilion, 2020). In this research, we extended these findings by adopting a quadripartite approach to passion and found that, in many cases, athletes are best served by having high HP that is combined with low OP. Focusing on how both passion dimensions combine within athletes can reveal more about how passion affects the experiences of athletes, and can also lead to some fascinating questions about the interplay between both HP and OP. We believe further research in this area will lead to exciting insights about the effects of passion in sport.

\section{References}

Amiot, C. E., Vallerand, R. J., \& Blanchard, C. M. (2006). Passion and psychological adjustment: A test of the person-environment fit hypothesis. Personality and Social Psychology Bulletin, 32(2), 220-229. https://doi.org/10.1177/0146167205280250

Araújo, C. G. S., \& Scharhag, J. (2016). Athlete: A working definition for medical and health sciences research. Scandinavian Journal of Medicine \& Science in Sports, 26(1), 4-7. https://doi.org/10.1111/sms.12632

Bartholomew, K. J., Ntoumanis, N., Ryan, R. M., \& Thøgersen-Ntoumani, C. (2011).

Psychological need thwarting in the sport context: Assessing the darker side of athletic experience. Journal of Sport and Exercise Psychology, 33, 75-102. https://doi.org/fs5m

Bélanger, J. J., Lafrenière, M.-A. K., Vallerand, R. J., \& Kruglanski, A. W. (2013a). Driven by fear: The effect of success and failure information on passionate individuals' performance. Journal of Personality and Social Psychology, 104(1), 180-195. https://doi.org/zk2

Bélanger, J. J., Lafrenière, M.-A. K., Vallerand, R. J., \& Kruglanski, A. W. (2013b). When 
passion makes the heart grow colder: The role of passion in alternative goal suppression. Journal of Personality and Social Psychology, 104, 126-147. https://doi.org/f4kjn3

Boardley, I. D., \& Kavussanu, M. (2008). The moral disengagement in sport scale-short. Journal of Sports Sciences, 26, 1507-1517. https://doi.org/10.1080/02640410802315054

Britton, D. M., Kavanagh, E. J., \& Polman, R. C. J. (2019). A path analysis of adolescent athletes' perceived stress reactivity, competition appraisals, emotions, coping, and performance satisfaction. Frontiers in Psychology, 10, 1151. https://doi.org/f3g9

Carron, A. V., Widmeyer, W. N., \& Brawley, L. R. (1985). The development of an instrument to assess cohesion in sport teams: The group environment questionnaire. Journal of Sport Psychology, 7, 244-266. https://doi.org/10.1123/jsp.7.3.244

Chan, D. K.-C., \& Hagger, M. S. (2012). Transcontextual development of motivation in sport injury prevention among elite athletes. Journal of Sport and Exercise Psychology, 34(5), 661-682. https://doi.org/10.1123/jsep.34.5.661

Cole, D. A., \& Maxwell, S. E. (2003). Testing mediational models with longitudinal data: Questions and tips in the use of structural equation modeling. Journal of Abnormal Psychology, 112, 558-577. https://doi.org/fcqc9r

Curran, T., Hill, A. P., Appleton, P. R., Vallerand, R. J., \& Standage, M. (2015). The psychology of passion: A meta-analytical review of a decade of research on intrapersonal outcomes. Motivation and Emotion, 39, 631-655. https://doi.org/f7q77b

Diener, E., Emmons, R. A., Larsen, R. J., \& Griffin, S. (1985). The Satisfaction with Life Scale. Journal of Personality Assessment, 49, 71-75.

Diener, E., Wirtz, D., Tov, W., Kim-Prieto, C., Choi, D., Oishi, S., \& Biswas-Diener, R. (2010). 
New well-being measures: Short scales to assess flourishing and positive and negative feelings. Social Indicators Research, 97, 143-156. https://doi.org/dd87vp

Dolan, S., Arterberry, B., \& Davis, A. (2021). A quadripartite model of passion for marijuana use: Associations with consumption, consequences, craving, and satisfaction with life. Addiction Research \& Theory, 29(1), 30-35. https://doi.org/f3d7

Foster, B. J., \& Chow, G. M. (2019). Development of the sport mental health continuum—short form. Journal of Clinical Sport Psychology, 13, 593-608. https://doi.org/fs5n

Gaudreau, P. (2012). A methodological note on the interactive and main effects of dualistic personality dimensions: An example using the $2 \times 2$ model of perfectionism. Personality and Individual Differences, 52, 26-31. https://doi.org/10.1016/j.paid.2011.08.022

Gaudreau, P., \& Blondin, J.-P. (2004). Differential associations of dispositional optimism and pessimism with coping, goal attainment, and emotional adjustment during sport competition. International Journal of Stress Management, 11, 245-269. https://doi.org/b9q46b

Gaudreau, P., Franche, V., \& Gareau, A. (2016). A latent mediated moderation of perfectionism, motivation, and academic satisfaction: Advancing the $2 \times 2$ model of perfectionism through substantive-methodological synergy. Journal of Psychoeducational Assessment, 34, 688-701. https://doi.org/10.1177/0734282916651778

Gustafsson, H., Hassmén, P., \& Hassmén, N. (2011). Are athletes burning out with passion? European Journal of Sport Science, 11, 387-395. https://doi.org/dvq5qf Jackson, S., Eklund, B., \& Martin, A. (2010). The FLOW manual: The manual for the flow scales. Mind Garden.

Jovanović, V. (2015). Beyond the PANAS: Incremental validity of the scale of positive and 
negative experience (SPANE) in relation to well-being. Personality and Individual Differences, 86, 487-491. https://doi.org/10.1016/j.paid.2015.07.015

Keyes, C. L. M., Wissing, M., Potgieter, J. P., Temane, M., Kruger, A., \& van Rooy, S. (2008). Evaluation of the mental health continuum-short form (MHC-SF) in setswana-speaking south africans. Clinical Psychology and Psychotherapy, 15(3), 181-192.

Kline, R. B. (2016). Principles and practice of structural equation modeling (4th edition). The Guilford Press.

Kowalski, K. C., \& Crocker, P. R. E. (2001). Development and validation of the coping function questionnaire for adolescents in sport. Journal of Sport and Exercise Psychology, 23, 136155. https://doi.org/10.1123/jsep.23.2.136

Li, F., \& Harmer, P. (1996). Confirmatory factor analysis of the group environment questionnaire with an intercollegiate sample. Journal of Sport and Exercise Psychology, 18(1), 49-63. https://doi.org/10.1123/jsep.18.1.49

Mageau, G. A., Vallerand, R. J., Charest, J., Salvy, S.-J., Lacaille, N., Bouffard, T., \& Koestner, R. (2009). On the development of harmonious and obsessive passion: The role of autonomy support, activity specialization, and identification with the activity. Journal of Personality, 77, 601-646. https://doi.org/bzb5rt

Marsh, H. W., Vallerand, R. J., Lafrenière, M.-A. K., Parker, P., Morin, A. J. S., Carbonneau, N., Jowett, S., Bureau, J. S., Fernet, C., Guay, F., Salah Abduljabbar, A., \& Paquet, Y. (2013). Passion: Does one scale fit all? Construct validity of two-factor passion scale and psychometric invariance over different activities and languages. Psychological Assessment, 25, 796-809. https://doi.org/fp69

Martin, E. M., \& Horn, T. S. (2013). The role of athletic identity and passion in predicting 
burnout in adolescent female athletes. The Sport Psychologist, 27, 338-348. https://doi.org/f5pd3w

McAuley, E., Duncan, T., \& Tammen, V. V. (1989). Psychometric properties of the intrinsic motivation inventory in a competitive sport setting: A confirmatory factor analysis. Research Quarterly for Exercise and Sport, 60, 48-58. https://doi.org/gd6dz4

Palan, S., \& Schitter, C. (2018). Prolific.ac_-A subject pool for online experiments. Journal of Behavioral and Experimental Finance, 17, 22-27. https://doi.org/gftct9

Pavot, W., \& Diener, E. (2008). The Satisfaction With Life Scale and the emerging construct of life satisfaction. The Journal of Positive Psychology, 3(2), 137-152. https://doi.org/dgn5p5

Peer, E., Brandimarte, L., Samat, S., \& Acquisti, A. (2017). Beyond the Turk: Alternative platforms for crowdsourcing behavioral research. Journal of Experimental Social Psychology, 70, 153-163. https://doi.org/10.1016/j.jesp.2017.01.006

Philippe, F. L., Vallerand, R. J., Houlfort, N., Lavigne, G. L., \& Donahue, E. G. (2010). Passion for an activity and quality of interpersonal relationships: The mediating role of emotions. Journal of Personality and Social Psychology, 98(6), 917-932. https://doi.org/ctrwj9

Richer, S. F., \& Vallerand, R. J. (1998). Construction and validation of the ÉSAS the relatedness feelings scale. European Review of Applied Psychology, 48, 129-137.

Scanlan, T. K., Carpenter, P. J., Simons, J. P., Schmidt, G. W., \& Keeler, B. (1993). The sport commitment model: Measurement development for the youth-sport domain. Journal of Sport and Exercise Psychology, 15, 16-38. https://doi.org/10.1123/jsep.15.1.16

Schellenberg, B. J. I., \& Bailis, D. S. (2015). Can passion be polyamorous? The impact of having multiple passions on subjective well-being and momentary emotions. Journal of Happiness Studies, 16, 1365-1381. https://doi.org/10.1007/s10902-014-9564-x 
Schellenberg, B. J. I., Mosewich, A. D., Bailis, D. S., Gaudreau, P., \& Verner-Filion, J. (2021). When self-compassion loses its luster: Ratings of self-compassionate and self-critical responding among passionate students. The Journal of Experimental Education, 89, 291305. https://doi.org/fp7j

Schellenberg, B. J. I., Verner-Filion, J., Gaudreau, P., Bailis, D. S., Lafrenière, M. -A. K., \& Vallerand, R. J. (2019). Testing the dualistic model of passion using a novel quadripartite approach: A look at physical and psychological well-being. Journal of Personality, 87, 163-180. https://doi.org/gc4jh3

Senécal, C. B., Vallerand, R. J., \& Vallières, E. F. (1992). Construction et validation de l'échelle de la qualité des relations interpersonnelles (EQRI). Revue Européenne de Psychologie Appliquée, 42, 315-322.

Smith, R. E., Smoll, F. L., Cumming, S. P., \& Grossbard, J. R. (2006). Measurement of multidimensional sport performance anxiety in children and adults: The sport anxiety scale-2. Journal of Sport and Exercise Psychology, 28, 479-501. https://doi.org/gftdqm

Standage, M., Duda, J. L., \& Ntoumanis, N. (2003). A model of contextual motivation in physical education: Using constructs from self-determination and achievement goal theories to predict physical activity intentions. Journal of Educational Psychology, 95, 97110. https://doi.org/10.1037/0022-0663.95.1.97

Standage, M., Duda, J. L., \& Ntoumanis, N. (2005). A test of self-determination theory in school physical education. British Journal of Educational Psychology, 75, 411-433. https://doi.org/bpgxcq

Stephan, Y., Deroche, T., Brewer, B. W., Caudroit, J., \& Le Scanff, C. (2009). Predictors of perceived susceptibility to sport-related injury among competitive runners: The role of 
previous experience, neuroticism, and passion for running. Applied Psychology, 58, 672687. https://doi.org/dwggkg

Vallerand, R. J. (1997). Toward a hierarchical model of intrinsic and extrinsic motivation. Advances in Experimental Social Psychology, 29, 271-360. https://doi.org/10.1016/S00652601(08)60019-2

Vallerand, R. J., Brière, N. M., Blanchard, C., \& Provencher, P. (1997). Development and validation of the multidimensional sportspersonship orientations scale. Journal of Sport and Exercise Psychology, 19, 197-206. https://doi.org/10.1123/jsep.19.2.197

Vallerand, R. J., Salvy, S.-J., Mageau, G. A., Elliot, A. J., Denis, P. L., Grouzet, F. M. E., \& Blanchard, C. (2007). On the role of passion in performance. Journal of Personality, 75, 505-534. https://doi.org/10.1111/j.1467-6494.2007.00447.x

Vallerand, R. J. (2015). The psychology of passion: A dualistic model. Oxford University Press.

Vallerand, R. J., \& Verner-Fillion, J. (2020). Theory and research in passion for sport and exercise. In G. Tenenbaum \& R. C. Eklund (Eds.), Handbook of sport psychology (pp. 206229). Wiley.

Verner-Filion, J., Vallerand, R. J., Amiot, C. E., \& Mocanu, I. (2017). The two roads from passion to sport performance and psychological well-being: The mediating role of need satisfaction, deliberate practice, and achievement goals. Psychology of Sport and Exercise, 30, 19-29. https://doi.org/10.1016/j.psychsport.2017.01.009

Van Yperen, N. W., Blaga, M., \& Postmes, T. (2014). A meta-analysis of self-reported achievement goals and nonself-report performance across three achievement domains (work, sports, and education). PLoS ONE, 9, e93594. https://doi.org/f5382v

\section{Figure Caption}


Figure 1. Associations between harmonious passion, obsessive passion, and outcome variables. Each plot displays results from Sample 1 (Panels A-D), Sample 2 (Panels E-O), or Sample 3 (Panels P-Y). High and low values of harmonious and obsessive passion are plotted at one standard deviation above and below the mean. Solid lines represent high obsessive passion; dotted lines represent low obsessive passion. Passion scores are mean centered and all outcomes are standardized. $\mathrm{PHP}=$ pure harmonious passion; $\mathrm{POP}=$ pure obsessive passion; $\mathrm{MP}=$ mixed passion; $\mathrm{NP}=$ non passion. 
Table 1

Results from Main Effects and Interactive Models

\begin{tabular}{|c|c|c|c|c|c|c|}
\hline & \multicolumn{3}{|c|}{ Main Effects Model } & \multicolumn{3}{|c|}{ Interactive Model } \\
\hline & HP & $\mathrm{OP}$ & $\mathrm{HP} \times \mathrm{OP}$ & HP & $\mathrm{OP}$ & $\mathrm{HP} \times \mathrm{OP}$ \\
\hline \multicolumn{7}{|l|}{ Sample 1} \\
\hline Enjoyment & $\begin{array}{c}0.384 * * \\
{[0.279,0.488]}\end{array}$ & $\begin{array}{c}-0.057 \\
{[-0.128,0.014]}\end{array}$ & $.000^{\mathrm{a}}$ & $\begin{array}{c}0.347 * * \\
{[0.238,0.456]}\end{array}$ & $\begin{array}{c}-0.018 \\
{[-0.130,0.094]}\end{array}$ & $\begin{array}{c}-0.080 \\
{[-0.206,0.046]}\end{array}$ \\
\hline Satisfaction with Life & $\begin{array}{c}0.644 * * \\
{[0.420,0.868]}\end{array}$ & $\begin{array}{c}-0.195 * \\
{[-0.368,-0.021]}\end{array}$ & $.000^{\mathrm{a}}$ & $\begin{array}{c}0.675 * * \\
{[0.450,0.901]}\end{array}$ & $\begin{array}{c}-0.227 * \\
{[-0.415,-0.039]}\end{array}$ & $\begin{array}{c}0.076 \\
{[-0.112,0.263]}\end{array}$ \\
\hline Stress & $\begin{array}{c}-0.120 \\
{[-0.281,0.040]}\end{array}$ & $\begin{array}{c}0.308 * * \\
{[0.163,0.454]}\end{array}$ & $.000^{\mathrm{a}}$ & $\begin{array}{c}-0.181 \\
{[-0.369,0.007]}\end{array}$ & $\begin{array}{c}0.363 * * \\
{[0.201,0.525]}\end{array}$ & $\begin{array}{c}-0.129 \\
{[-0.299,0.041]}\end{array}$ \\
\hline Worry & $\begin{array}{c}-0.012 \\
{[-0.133,0.109]}\end{array}$ & $\begin{array}{c}0.187 * * \\
{[0.086,0.287]}\end{array}$ & $.000^{\mathrm{a}}$ & $\begin{array}{c}-0.056 \\
{[-0.190,0.077]}\end{array}$ & $\begin{array}{c}0.229 * * \\
{[0.112,0.346]}\end{array}$ & $\begin{array}{c}-0.098 \\
{[-0.212,0.015]}\end{array}$ \\
\hline \multicolumn{7}{|l|}{ Sample 2} \\
\hline Flow & $\begin{array}{c}0.529 * * \\
{[0.357,0.700]}\end{array}$ & $\begin{array}{c}-0.011 \\
{[-0.064,0.042]}\end{array}$ & $.000^{\mathrm{a}}$ & $\begin{array}{c}0.585 * * \\
{[0.404,0.766]}\end{array}$ & $\begin{array}{c}-0.040 \\
{[-0.105,0.025]}\end{array}$ & $\begin{array}{c}0.088^{*} \\
{[0.004,0.171]}\end{array}$ \\
\hline Subjective Well-being & $\begin{array}{c}0.870 * * \\
{[0.595,1.145]}\end{array}$ & $\begin{array}{c}0.080 \\
{[-0.010,0.170]}\end{array}$ & $.000^{\mathrm{a}}$ & $\begin{array}{c}0.807 * * \\
{[0.542,1.072]}\end{array}$ & $\begin{array}{c}0.114^{*} \\
{[0.015,0.214]}\end{array}$ & $\begin{array}{c}-0.105 \\
{[-0.231,0.022]}\end{array}$ \\
\hline Social Well-being & $\begin{array}{c}1.355 * * \\
{[0.933,1.776]}\end{array}$ & $\begin{array}{c}-0.049 \\
{[-0.170,0.071]}\end{array}$ & $.000^{\mathrm{a}}$ & $\begin{array}{c}1.343 * * \\
{[0.932,1.754]}\end{array}$ & $\begin{array}{c}-0.040 \\
{[-0.169,0.089]}\end{array}$ & $\begin{array}{c}-0.031 \\
{[-0.188,0.127]}\end{array}$ \\
\hline Psychological Well-being & $\begin{array}{c}1.134 * * \\
{[0.800,1.468]}\end{array}$ & $\begin{array}{c}0.018 \\
{[-0.078,0.113]}\end{array}$ & $.000^{\mathrm{a}}$ & $\begin{array}{c}1.140 * * \\
{[0.796,1.483]}\end{array}$ & $\begin{array}{c}0.018 \\
{[-0.087,0.122]}\end{array}$ & $\begin{array}{c}-0.006 \\
{[-0.126,0.113]}\end{array}$ \\
\hline Positive Affect & $\begin{array}{c}0.501 * * \\
{[0.350,0.651]}\end{array}$ & $\begin{array}{c}-0.099 * * \\
{[-0.153,-0.045]}\end{array}$ & $.000^{\mathrm{a}}$ & $\begin{array}{c}0.583 * * \\
{[0.423,0.742]}\end{array}$ & $\begin{array}{c}-0.143^{* *} \\
{[-0.208,-0.079]}\end{array}$ & $\begin{array}{c}0.130^{* *} \\
{[0.036,0.223]}\end{array}$ \\
\hline Negative Affect & $\begin{array}{c}-0.299 * * \\
{[-0.449,-0.150]}\end{array}$ & $\begin{array}{c}0.236 * * \\
{[0.154,0.319]}\end{array}$ & $.000^{\mathrm{a}}$ & $\begin{array}{c}-0.355 * * \\
{[-0.537,-0.172]}\end{array}$ & $\begin{array}{c}0.265 * * \\
{[0.173,0.357]}\end{array}$ & $\begin{array}{c}-0.085 \\
{[-0.201,0.032]}\end{array}$ \\
\hline Mastery Goals & $\begin{array}{c}1.016 * * \\
{[0.754,1.277]}\end{array}$ & $\begin{array}{c}-0.060 \\
{[-0.139,0.018]}\end{array}$ & $.000^{\mathrm{a}}$ & $\begin{array}{c}0.975 * * \\
{[0.711,1.239]}\end{array}$ & $\begin{array}{c}-0.039 \\
{[-0.119,0.041]}\end{array}$ & $\begin{array}{c}-0.066 \\
{[-0.158,0.027]}\end{array}$ \\
\hline Improvement Goals & $\begin{array}{c}1.019 * * \\
{[0.692,1.346]}\end{array}$ & $\begin{array}{c}0.064 \\
{[-0.066,0.193]}\end{array}$ & $.000^{\mathrm{a}}$ & $\begin{array}{c}0.983 * * \\
{[0.646,1.320]}\end{array}$ & $\begin{array}{c}0.082 \\
{[-0.044,0.208]}\end{array}$ & $\begin{array}{c}-0.059 \\
{[-0.226,0.107]}\end{array}$ \\
\hline Performance Goals & $\begin{array}{c}0.811 * * \\
{[0.479,1.143]}\end{array}$ & $\begin{array}{c}0.351 * * \\
{[0.198,0.505]}\end{array}$ & $.000^{\mathrm{a}}$ & $\begin{array}{c}0.772 * * \\
{[0.426,1.117]}\end{array}$ & $\begin{array}{c}0.371 * * \\
{[0.221,0.520]}\end{array}$ & $\begin{array}{c}-0.064 \\
{[-0.233,0.106]}\end{array}$ \\
\hline Injury History & $\begin{array}{c}0.084 \\
{[-0.110,0.278]}\end{array}$ & $\begin{array}{c}0.190 * * \\
{[0.085,0.295]}\end{array}$ & $.000^{\mathrm{a}}$ & $\begin{array}{c}0.090 \\
{[-0.176,0.355]}\end{array}$ & $\begin{array}{c}0.188 * * \\
{[0.063,0.313]}\end{array}$ & $\begin{array}{c}0.008 \\
{[-0.148,0.163]}\end{array}$ \\
\hline Injury Likelihood & $\begin{array}{c}0.066 \\
{[-0.145,0.276]}\end{array}$ & $\begin{array}{c}0.232 * * \\
{[0.130,0.335]}\end{array}$ & $.000^{\mathrm{a}}$ & $\begin{array}{c}0.042 \\
{[-0.209,0.293]}\end{array}$ & $\begin{array}{c}0.243 * * \\
{[0.131,0.354]}\end{array}$ & $\begin{array}{c}-0.034 \\
{[-0.171,0.103]}\end{array}$ \\
\hline \multicolumn{7}{|l|}{ Sample 3} \\
\hline Relatedness & $\begin{array}{c}0.970 * * \\
{[0.705,1.236]}\end{array}$ & $\begin{array}{c}-0.175^{*} \\
{[-0.311,-0.039]}\end{array}$ & $.000^{\mathrm{a}}$ & $\begin{array}{c}1.015^{* *} \\
{[0.736,1.294]}\end{array}$ & $\begin{array}{c}-0.223^{*} \\
{[-0.393,-0.053]}\end{array}$ & $\begin{array}{c}0.086 \\
{[-0.042,0.214]}\end{array}$ \\
\hline
\end{tabular}




\begin{tabular}{|c|c|c|c|c|c|c|}
\hline Competence & $\begin{array}{c}1.042 * * \\
{[0.761,1.323]}\end{array}$ & $\begin{array}{c}0.145 \\
{[-0.006,0.296]}\end{array}$ & $.000^{\mathrm{a}}$ & $\begin{array}{c}0.998 * * \\
{[0.717,1.279]}\end{array}$ & $\begin{array}{c}0.193^{*} \\
{[0.018,0.367]}\end{array}$ & $\begin{array}{c}-0.089 \\
{[-0.218,0.041]}\end{array}$ \\
\hline & $0.769 * *$ & $-0.144 *$ & & $0.820 * *$ & $-0.196^{*}$ & 0.089 \\
\hline Autonomy & {$[0.536,1.002]$} & {$[-0.278,-0.011]$} & $.000^{a}$ & {$[0.567,1.072]$} & {$[-0.374,-0.018]$} & {$[-0.055,0.233]$} \\
\hline & $0.941 * *$ & $-0.372 * *$ & $000^{\mathrm{a}}$ & $0.979 * *$ & $-0.408 * *$ & 0.070 \\
\hline Conesion & {$[0.660,1.222]$} & {$[-0.529,-0.214]$} & $.000^{a}$ & {$[0.679,1.280]$} & {$[-0.577,-0.239]$} & {$[-0.084,0.224]$} \\
\hline Moral Disengagement & $\begin{array}{c}-0.166 \\
{[-0.371,0.040]}\end{array}$ & $\begin{array}{c}0.448 * * \\
{[0.250,0.645]}\end{array}$ & $.000^{\mathrm{a}}$ & $\begin{array}{c}-0.249 * \\
{[-0.497,-0.001]}\end{array}$ & $\begin{array}{c}0.515 * * \\
{[0.299,0.731]}\end{array}$ & $\begin{array}{c}-0.130 \\
{[-0.291,0.031]}\end{array}$ \\
\hline Sportspersonship & $\begin{array}{c}0.430 * * \\
{[0.278,0.583]}\end{array}$ & $\begin{array}{c}-0.160 * * \\
{[-0.240,-0.080]}\end{array}$ & $.000^{\mathrm{a}}$ & $\begin{array}{c}0.472 * * \\
{[0.310,0.634]}\end{array}$ & $\begin{array}{c}-0.198 * * \\
{[-0.300,-0.095]}\end{array}$ & $\begin{array}{c}0.065 \\
{[-0.017,0.148]}\end{array}$ \\
\hline Relationship Quality & $\begin{array}{c}0.498 * * \\
{[0.342,0.654]}\end{array}$ & $\begin{array}{c}-0.067 \\
{[-0.146,0.013]}\end{array}$ & $.000^{\mathrm{a}}$ & $\begin{array}{c}0.534 * * \\
{[0.366,0.702]}\end{array}$ & $\begin{array}{c}-0.105^{*} \\
{[-0.206,-0.004]}\end{array}$ & $\begin{array}{c}0.070 \\
{[-0.003,0.144]}\end{array}$ \\
\hline NT - Relatedness & $\begin{array}{c}-0.644 * * \\
{[-0.892,-0.395]}\end{array}$ & $\begin{array}{c}0.557 * * \\
{[0.365,0.748]}\end{array}$ & $.000^{\mathrm{a}}$ & $\begin{array}{c}-0.821 * * \\
{[-1.149,-0.492]}\end{array}$ & $\begin{array}{c}0.695 * * \\
{[0.472,0.918]}\end{array}$ & $\begin{array}{c}-0.253 * \\
{[-0.464,-0.043]}\end{array}$ \\
\hline NT - Competence & $\begin{array}{c}-0.648 * * \\
{[-0.896,-0.400]}\end{array}$ & $\begin{array}{c}0.653 * * \\
{[0.476,0.831]}\end{array}$ & $.000^{\mathrm{a}}$ & $\begin{array}{c}-0.833 * * \\
{[-1.168,-0.498]}\end{array}$ & $\begin{array}{c}0.799 * * \\
{[0.582,1.016]}\end{array}$ & $\begin{array}{c}-0.269 * \\
{[-0.500,-0.038]}\end{array}$ \\
\hline NT - Autonomy & $\begin{array}{c}-0.466 * * \\
{[-0.710,-0.221]}\end{array}$ & $\begin{array}{c}0.547 * * \\
{[0.353,0.740]}\end{array}$ & $.000^{\mathrm{a}}$ & $\begin{array}{c}-0.593 * * \\
{[-0.877,-0.308]}\end{array}$ & $\begin{array}{c}0.647 * * \\
{[0.441,0.853]}\end{array}$ & $\begin{array}{c}-0.193 * \\
{[-0.368,-0.018]}\end{array}$ \\
\hline
\end{tabular}

Note. Unstandardized beta coefficients are reported with $95 \%$ confidence intervals in brackets. ${ }^{\text {a }}$ Identifies parameters that were fixed at zero. HP $=$ harmonious passion. $\mathrm{OP}=$ obsessive passion. $\mathrm{NT}=$ need thwarting. $* p \leq .05 . * * p \leq .01$ 
Table 2

Association Between Passion Subtypes and Outcome Variables

\begin{tabular}{|c|c|c|c|c|c|}
\hline Outcome Variable & $d$ & Description & $B$ & $S E$ & $95 \% \mathrm{CI}$ \\
\hline \multicolumn{6}{|l|}{ Sample 1} \\
\hline \multicolumn{6}{|l|}{ Enjoyment } \\
\hline H1: PHP v. POP & $1.227 * *$ & ----- & ----- & ----- & ----- \\
\hline H2: MP v. PHP & -0.183 & OP main effect & -0.057 & 0.036 & {$[-0.128,0.014]$} \\
\hline H3: PHP v. NP & $1.044 * *$ & HP main effect & $0.384 * *$ & 0.053 & {$[0.279,0.488]$} \\
\hline H4: MP v. POP & $1.044 * *$ & HP main effect & $0.384 * *$ & 0.053 & {$[0.279,0.488]$} \\
\hline H5: POP v. NP & -0.183 & OP main effect & -0.057 & 0.036 & {$[-0.128,0.014]$} \\
\hline H6: MP v. NP & $0.861 * *$ & ----- & ----- & ----- & ---- \\
\hline \multicolumn{6}{|l|}{ Satisfaction with Life } \\
\hline H1: PHP v. POP & $1.154 * *$ & ----- & ----- & ----- & ----- \\
\hline H2: MP v. PHP & $-0.303^{*}$ & OP main effect & $-0.195^{*}$ & 0.089 & {$[-0.368,-0.021]$} \\
\hline H3: PHP v. NP & $0.851 * *$ & HP main effect & $0.644 * *$ & 0.114 & {$[0.420,0.868]$} \\
\hline H4: MP v. POP & $0.851 * *$ & HP main effect & $0.644 * *$ & 0.114 & {$[0.420,0.868]$} \\
\hline H5: POP v. NP & $-0.303 *$ & OP main effect & $-0.195 *$ & 0.089 & {$[-0.368,-0.021]$} \\
\hline H6: MP v. NP & $0.548 * *$ & ----- & ----- & ----- & ----- \\
\hline \multicolumn{6}{|l|}{ Stress } \\
\hline H1: PHP v. POP & $-0.790 * *$ & ----- & ----- & ----- & ----- \\
\hline H2: MP v. PHP & $0.595 * *$ & OP main effect & $0.308 * *$ & 0.074 & {$[0.163,0.454]$} \\
\hline H3: PHP v. NP & -0.196 & HP main effect & -0.120 & 0.082 & {$[-0.281,0.040]$} \\
\hline H4: MP v. POP & -0.196 & HP main effect & -0.120 & 0.082 & {$[-0.281,0.040]$} \\
\hline H5: POP v. NP & $0.595 * *$ & OP main effect & $0.308 * *$ & 0.074 & {$[0.163,0.454]$} \\
\hline H6: MP v. NP & $0.399 * *$ & ----- & ----- & ----- & ----- \\
\hline \multicolumn{6}{|l|}{ Worry } \\
\hline H1: PHP v. POP & $-0.529 *$ & ----- & ----- & ----- & ----- \\
\hline H2: MP v. PHP & $0.502 * *$ & OP main effect & $0.187 * *$ & 0.051 & {$[0.086,0.287]$} \\
\hline H3: PHP v. NP & -0.027 & HP main effect & -0.012 & 0.062 & {$[-0.133,0.109]$} \\
\hline H4: MP v. POP & -0.027 & HP main effect & -0.012 & 0.062 & {$[-0.133,0.109]$} \\
\hline H5: POP v. NP & $0.502 * *$ & OP main effect & $0.187 * *$ & 0.051 & {$[0.086,0.287]$} \\
\hline H6: MP v. NP & $0.474 * *$ & ----- & ----- & ----- & ----- \\
\hline \multicolumn{6}{|l|}{ Sample 2} \\
\hline \multicolumn{6}{|l|}{ Flow } \\
\hline H1: PHP v. POP & $1.418 * *$ & ----- & ----- & ----- & ----- \\
\hline H2: MP v. PHP & 0.058 & OP at High HP & 0.013 & 0.028 & {$[-0.043,0.069]$} \\
\hline H3: PHP v. NP & $1.006 * *$ & HP at Low OP & $0.474 * *$ & 0.090 & {$[0.299,0.650]$} \\
\hline H4: MP v. POP & $1.476^{* *}$ & HP at High OP & $0.696 * *$ & 0.122 & {$[0.458,0.934]$} \\
\hline H5: POP v. NP & -0.412 & OP at Low HP & -0.094 & 0.052 & {$[-0.196,0.009]$} \\
\hline
\end{tabular}


H6: MP v. NP

Subjective Well-being

H1: PHP v. POP

H2: MP v. PHP

H3: PHP v. NP

H4: MP v. POP

H5: POP v. NP

H6: MP v. NP

Social Well-being

H1: PHP v. POP

H2: MP v. PHP

H3: PHP v. NP

H4: MP v. POP

H5: POP v. NP

H6: MP v. NP

Psychological Well-being

H1: PHP v. POP

H2: MP v. PHP

H3: PHP v. NP

H4: MP v. POP

H5: POP v. NP

H6: MP v. NP

Positive Affect

H1: PHP v. POP

H2: MP v. PHP

H3: PHP v. NP

H4: MP v. POP

H5: POP v. NP

H6: MP v. NP

Negative Affect

H1: PHP v. POP

H2: MP v. PHP

H3: PHP v. NP

H4: MP v. POP

H5: POP v. NP

H6: MP v. NP

Mastery Goals

H1: PHP v. POP

H2: MP v. PHP

H3: PHP v. NP
$1.065 * *$

$0.856^{* *}$

0.201

$1.056 * *$

$1.056 * *$

0.201

$1.257 * *$

$1.346 * *$

$-0.094$

$1.252 * *$

$1.252 * *$

$-0.094$

$1.159 * *$

$1.197 * *$

0.039

$1.236^{* *}$

$1.236^{* * *}$

0.039

$1.276^{* *}$

$2.040 * *$

$-0.298 *$

$0.976^{* *}$

$1.743 * *$

$-1.064 * *$

$0.679 * *$

$-1.423 * *$

$0.877 * *$

$-0.546 * *$

$-0.546 * *$

$0.877 * *$

$0.331 * *$

$1.770 * *$

$-0.186$

$1.584 * *$
OP main effect

HP main effect

HP main effect

OP main effect

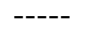

OP main effect

HP main effect

HP main effect

OP main effect

$$
\text { ----- }
$$

OP main effect

HP main effect

HP main effect

OP main effect

$$
\text { ----- }
$$

OP at High HP

$\mathrm{HP}$ at Low OP

$\mathrm{HP}$ at High OP

OP at Low HP

$$
\text { ----- }
$$

OP main effect

HP main effect

HP main effect

OP main effect

$$
\text { ----- }
$$

OP main effect

HP main effect

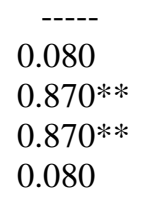

0.046

0.140

0.140

0.046

-----

-----

$-0.049$

$1.355^{* *}$

$1.355^{* *}$

$-0.049$

0.061

0.215

0.215

0.061

---- -----

0.018

$1.134 * *$

$1.134 * *$

0.018

0.049

0.170

0.170

0.049

$----$

$-0.063^{*}$

$0.418 * *$

$0.747 * *$

$-0.224 * *$

0.031

0.082

0.118

0.055

$$
\text { ----- }
$$

$0.236 * *$

$-0.299 * *$

$-0.299 * *$

$0.236 * *$

$$
\text { ----- }
$$

$-0.060$

$1.016 * *$

$$
\text { ----- }
$$

0.042

0.076

0.076

0.042

0.040
$[-0.010,0.170]$

$[0.595,1.145]$

$[0.595,1.145]$

$[-0.010,0.170]$

$[-0.170,0.071]$ $[0.933,1.776]$

$[0.933,1.776]$

$[-0.170,0.071]$

[-0.078, 0.113]

$[0.800,1.468]$

$[0.800,1.468]$

$[-0.078,0.113]$

$[-0.124,-0.001]$

$[0.259,0.578]$

$[0.515,0.978]$

$[-0.331,-0.117]$

[0.154, 0.319]

$[-0.449,-0.150]$

$[-0.449,-0.150]$

[0.154, 0.319]

$[-0.139,0.018]$

$[0.754,1.277]$ 


\begin{tabular}{|c|c|}
\hline H4: MP v. POP & $1.584 * *$ \\
\hline H5: POP v. NP & -0.186 \\
\hline H6: MP v. NP & $1.398 * *$ \\
\hline \multicolumn{2}{|l|}{ Improvement Goals } \\
\hline H1: PHP v. POP & $0.941 * *$ \\
\hline H2: MP v. PHP & 0.133 \\
\hline H3: PHP v. NP & $1.074 * *$ \\
\hline H4: MP v. POP & $1.074 * *$ \\
\hline H5: POP v. NP & 0.133 \\
\hline H6: MP v. NP & $1.207 * *$ \\
\hline \multicolumn{2}{|l|}{ Performance Goals } \\
\hline H1: PHP v. POP & 0.102 \\
\hline H2: MP v. PHP & $0.629 * *$ \\
\hline H3: PHP v. NP & $0.731 * *$ \\
\hline H4: MP v. POP & $0.731 * *$ \\
\hline H5: POP v. NP & $0.629 * *$ \\
\hline H6: MP v. NP & $1.360 * *$ \\
\hline \multicolumn{2}{|l|}{ Injury History } \\
\hline H1: PHP v. POP & -0.381 \\
\hline H2: MP v. PHP & $0.481 * *$ \\
\hline H3: PHP v. NP & 0.100 \\
\hline H4: MP v. POP & 0.100 \\
\hline H5: POP v. NP & $0.481 * *$ \\
\hline H6: MP v. NP & $0.581 * *$ \\
\hline \multicolumn{2}{|l|}{ Injury Likelihood } \\
\hline H1: PHP v. POP & $-0.510 *$ \\
\hline H2: MP v. PHP & $0.588 * *$ \\
\hline H3: PHP v. NP & 0.078 \\
\hline H4: MP v. POP & 0.078 \\
\hline H5: POP v. NP & $0.588 * *$ \\
\hline H6: MP v. NP & $0.667 * *$ \\
\hline \multicolumn{2}{|l|}{ imple 3} \\
\hline \multicolumn{2}{|l|}{ Relatedness } \\
\hline H1: PHP v. POP & $1.702 * *$ \\
\hline H2: MP v. PHP & $-0.356^{*}$ \\
\hline H3: PHP v. NP & $1.346^{* *}$ \\
\hline H4: MP v. POP & $1.346^{* *}$ \\
\hline H5: POP v. NP & $-0.356^{*}$ \\
\hline H6: MP v. NP & $0.990 * *$ \\
\hline
\end{tabular}

$\begin{array}{ccc}\text { HP main effect } & 1.016^{* *} & 0.133 \\ \text { OP main effect } & -0.060 & 0.040 \\ ----- & ---- & ---- \\ ---- & ---- & ---- \\ \text { OP main effect } & 0.064 & 0.066 \\ \text { HP main effect } & 1.019 * * & 0.167 \\ \text { HP main effect } & 1.019 * * & 0.167 \\ \text { OP main effect } & 0.064 & 0.066\end{array}$

$\begin{array}{lc}----- & ----- \\ ----- & ---- \\ 0.351 * * & 0.078 \\ 0.811^{* *} & 0.169 \\ 0.811^{* *} & 0.169 \\ 0.351 * * & 0.078 \\ ----- & -----\end{array}$

OP main effect

HP main effect

HP main effect

OP main effect

OP main effect

HP main effect

HP main effect

OP main effect

$0.190 * *$

0.084

0.084

$0.190 * *$

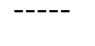

OP main effect

HP main effect

HP main effect

OP main effect

$1.702 * *$

$1.346^{* *}$

$-0.356^{*}$

$0.990 * *$

$0.232 * * \quad 0.053$

$0.066 \quad 0.107$

$0.066 \quad 0.107$

$0.232 * * \quad 0.053$

OP main effect

HP main effect

$-0.175 *$

0.070

$0.970 * * \quad 0.135$

HP main effect

$0.970 * *$

0.135

$-0.175^{*}$

0.070

-----

$-----$
[0.754, 1.277]

$[-0.139,0.018]$

$0.066,0.193]$

$[0.692,1.346]$

$[0.692,1.346]$

$[-0.066,0.193]$

[0.198, 0.505]

$[0.479,1.143]$

$[0.479,1.143]$

$[0.198,0.505]$

$[0.085,0.295]$

$[-0.110,0.278]$

$[-0.110,0.278]$

$[0.085,0.295]$

$[0.130,0.335]$

$[-0.145,0.276]$

$[-0.145,0.276]$

$[0.130,0.335]$

OP main effect

$[-0.311,-0.039]$

$[0.705,1.236]$

$[0.705,1.236]$

[-0.311, -0.039]

Competence 


\begin{tabular}{|c|c|}
\hline H1: PHP v. POP & $0.991 * *$ \\
\hline H2: MP v. PHP & 0.256 \\
\hline H3: PHP v. NP & $1.246 * *$ \\
\hline H4: MP v. POP & $1.246 * *$ \\
\hline H5: POP v. NP & 0.256 \\
\hline H6: MP v. NP & $1.502 * *$ \\
\hline \multicolumn{2}{|l|}{ Autonomy } \\
\hline H1: PHP v. POP & $1.552 * *$ \\
\hline H2: MP v. PHP & $-0.329 *$ \\
\hline H3: PHP v. NP & $1.223 * *$ \\
\hline H4: MP v. POP & $1.223^{* *}$ \\
\hline H5: POP v. NP & $-0.329 *$ \\
\hline H6: MP v. NP & $0.894 * *$ \\
\hline \multicolumn{2}{|l|}{ Cohesion } \\
\hline H1: PHP v. POP & $2.123 * *$ \\
\hline H2: MP v. PHP & $-0.791 * *$ \\
\hline H3: PHP v. NP & $1.332 * *$ \\
\hline H4: MP v. POP & $1.332 * *$ \\
\hline H5: POP v. NP & $-0.791 * *$ \\
\hline H6: MP v. NP & $0.541 * *$ \\
\hline \multicolumn{2}{|c|}{ Moral Disengagement } \\
\hline H1: PHP v. POP & $-1.319 * *$ \\
\hline H2: MP v. PHP & $1.053 * *$ \\
\hline H3: PHP v. NP & -0.267 \\
\hline H4: MP v. POP & -0.267 \\
\hline H5: POP v. NP & $1.053 * *$ \\
\hline H6: MP v. NP & $0.786^{* *}$ \\
\hline \multicolumn{2}{|l|}{ Sportspersonship } \\
\hline H1: PHP v. POP & $1.681 * *$ \\
\hline H2: MP v. PHP & $-0.593 * *$ \\
\hline H3: PHP v. NP & $1.087 * *$ \\
\hline H4: MP v. POP & $1.087 * *$ \\
\hline H5: POP v. NP & $-0.593 * *$ \\
\hline H6: MP v. NP & $0.494 * *$ \\
\hline \multicolumn{2}{|l|}{ Relationship Quality } \\
\hline H1: PHP v. POP & $1.515^{* *}$ \\
\hline H2: MP v. PHP & -0.250 \\
\hline H3: PHP v. NP & $1.265 * *$ \\
\hline H4: MP v. POP & $1.265^{* *}$ \\
\hline H5: POP v. NP & -0.250 \\
\hline
\end{tabular}

\begin{tabular}{|c|c|c|}
\hline ----- & ----- & ----- \\
\hline OP main effect & 0.145 & 0.077 \\
\hline HP main effect & $1.042 * *$ & 0.143 \\
\hline HP main effect & $1.042 * *$ & 0.143 \\
\hline OP main effect & 0.145 & 0.077 \\
\hline ----- & ----- & ----- \\
\hline ----- & ----- & ----- \\
\hline OP main effect & $-0.144 *$ & 0.068 \\
\hline HP main effect & $0.769 * *$ & 0.119 \\
\hline HP main effect & $0.769 * *$ & 0.119 \\
\hline OP main effect & $-0.144^{*}$ & 0.068 \\
\hline ----- & ----- & ----- \\
\hline ----- & ----- & ----- \\
\hline OP main effect & $-0.372 * *$ & 0.080 \\
\hline HP main effect & $0.941 * *$ & 0.144 \\
\hline HP main effect & $0.941 * *$ & 0.144 \\
\hline OP main effect & $-0.372 * *$ & 0.080 \\
\hline ----- & ----- & ----- \\
\hline ----- & ----- & ----- \\
\hline OP main effect & $0.448 * *$ & 0.101 \\
\hline HP main effect & -0.166 & 0.105 \\
\hline HP main effect & -0.166 & 0.105 \\
\hline OP main effect & $0.448 * *$ & 0.101 \\
\hline ----- & ----- & ----- \\
\hline ----- & ----- & ----- \\
\hline OP main effect & $-0.160 * *$ & 0.041 \\
\hline HP main effect & $0.430 * *$ & 0.078 \\
\hline HP main effect & $0.430 * *$ & 0.078 \\
\hline OP main effect & $-0.160 * *$ & 0.041 \\
\hline ----- & ----- & ----- \\
\hline ----- & ----- & ----- \\
\hline OP main effect & -0.067 & 0.041 \\
\hline HP main effect & $0.498 * *$ & 0.080 \\
\hline HP main effect & $0.498 * *$ & 0.080 \\
\hline OP main effect & -0.067 & 0.041 \\
\hline
\end{tabular}

$[-0.006,0.296]$
$[0.761,1.323]$
$[0.761,1.323]$
$[-0.006,0.296]$

[-0.278, -0.011]

$[0.536,1.002]$

$[0.536,1.002]$

$[-0.278,-0.011]$

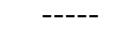

$[-0.529,-0.214]$
$[0.660,1.222]$
$[0.660,1.222]$
$[-0.529,-0.214]$

-----

$[0.250,0.645]$

$[-0.371,0.040]$

$[-0.371,0.040]$

$[0.250,0.645]$

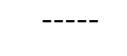

$[-0.240,-0.080]$

$[0.278,0.583]$

$[0.278,0.583]$

$[-0.240,-0.080]$

$[-0.146,0.013]$

[0.342, 0.654]

$[0.342,0.654]$

$[-0.146,0.013]$ 
H6: MP v. NP

Need Thwarting - Relatedness

H1: PHP v. POP

H2: MP v. PHP

H3: PHP v. NP

H4: MP v. POP

H5: POP v. NP

H6: MP v. NP

Need Thwarting - Competence

H1: PHP v. POP

H2: MP v. PHP

H3: PHP v. NP

H4: MP v. POP

H5: POP v. NP

H6: MP v. NP

Need Thwarting - Autonomy

H1: PHP v. POP

H2: MP v. PHP

H3: PHP v. NP

H4: MP v. POP

H5: POP v. NP

H6: MP v. NP

$1.016 * *$
$-2.727 * *$
$1.078 * *$
$-0.770 * *$
$-1.649 * *$
$1.957 * *$
0.308
$-2.667 * *$
$1.146 * *$
$-0.683 * *$
$-1.520 * *$
$1.984 * *$
$0.463 *$

$-2.139 * *$
$1.008 * *$
$-0.504 * *$
$-1.131 * *$
$1.635 * *$
$0.504 * *$

OP at High HP

HP at Low OP

$\mathrm{HP}$ at High OP

OP at Low HP

$-----$

OP at High HP

$\mathrm{HP}$ at Low OP

$\mathrm{HP}$ at High OP

OP at Low HP

-----

OP at High HP

HP at Low OP

HP at High OP

OP at Low HP

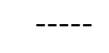

$0.494 * *$

$-0.522 * *$

$-1.119 * *$

$0.896 * *$

0.107

0.127

0.269

0.171

$-----$

$0.585^{* *}$

$-0.516^{* *}$

$-1.149 * *$

$1.012 * *$

0.104

0.129

0.283

0.177

$$
----
$$

$0.494 * *$
$-0.365^{* *}$
$-0.820^{* *}$
$0.800^{* *}$

0.108

0.128

0.219

0.143
[0.284, 0.704]

$[-0.772,-0.273]$

$[-1.645,-0.592]$

$[0.562,1.231]$

$----$

[0.382, 0.788]

$[-0.769,-0.264]$

$[-1.705,-0.594]$

[0.665, 1.359]

[0.283, 0.704]

$[-0.617,-0.114]$

$[-1.249,-0.391]$

$[0.519,1.081]$

Note. $\mathrm{H} 1-\mathrm{H} 6$ corresponds to hypotheses 1 to 6 . Unstandardized beta coefficients are reported. $\mathrm{PHP}=$ pure harmonious passion. $\mathrm{POP}=$ pure obsessive passion. $\mathrm{MP}=$ mixed passion. $\mathrm{NP}=$ non-passion. $\mathrm{HP}=$ harmonious passion. $\mathrm{OP}=$ obsessive passion. $* p \leq .05$. $* * x \leq .01$ 
Table 3

Summary of Hypotheses

\begin{tabular}{|c|c|c|c|c|c|c|c|c|c|}
\hline & & H1 & $\mathrm{H} 2$ & H3 & $\mathrm{H} 4$ & H5a & $\mathrm{H} 5 \mathrm{~b}$ & H6a & $\mathrm{H} 6 \mathrm{~b}$ \\
\hline Dependent Variable & Sample & $\mathrm{PHP}>\mathrm{POP}$ & $\mathrm{PHP}>\mathrm{MP}$ & $\mathrm{PHP}>\mathrm{NP}$ & $\mathrm{POP}<\mathrm{MP}$ & $\mathrm{POP}>\mathrm{NP}$ & $\mathrm{POP}<\mathrm{NP}$ & $\mathrm{MP}>\mathrm{NP}$ & $\mathrm{MP}<\mathrm{NP}$ \\
\hline Enjoyment & 1 & $\checkmark$ & $x$ & $\checkmark$ & $\checkmark$ & $x$ & $x$ & $\checkmark$ & $x$ \\
\hline Satisfaction with Life & 1 & $\checkmark$ & $\checkmark$ & $\checkmark$ & $\checkmark$ & $x$ & $\checkmark$ & $\checkmark$ & $x$ \\
\hline Stress & 1 & $\checkmark$ & $\checkmark$ & $x$ & $x$ & $x$ & $\checkmark$ & $x$ & $\checkmark$ \\
\hline Worry & 1 & $\checkmark$ & $\checkmark$ & $x$ & $x$ & $x$ & $\checkmark$ & $x$ & $\checkmark$ \\
\hline Flow & 2 & $\checkmark$ & $x$ & $\checkmark$ & $\checkmark$ & $x$ & $x$ & $\checkmark$ & $x$ \\
\hline Subjective Well-being & 2 & $\checkmark$ & $x$ & $\checkmark$ & $\checkmark$ & $x$ & $x$ & $\checkmark$ & $x$ \\
\hline Social Well-being & 2 & $\checkmark$ & $x$ & $\checkmark$ & $\checkmark$ & $x$ & $x$ & $\checkmark$ & $x$ \\
\hline Psychological Well-being & 2 & $\checkmark$ & $x$ & $\checkmark$ & $\checkmark$ & $x$ & $x$ & $\checkmark$ & $x$ \\
\hline Positive Affect & 2 & $\checkmark$ & $\checkmark$ & $\checkmark$ & $\checkmark$ & $x$ & $\checkmark$ & $\checkmark$ & $x$ \\
\hline Negative Affect & 2 & $\checkmark$ & $\checkmark$ & $\checkmark$ & $\checkmark$ & $x$ & $\checkmark$ & $x$ & $\checkmark$ \\
\hline Mastery Goals & 2 & $\checkmark$ & $x$ & $\checkmark$ & $\checkmark$ & $x$ & $x$ & $\checkmark$ & $x$ \\
\hline Improvement Goals & 2 & $\checkmark$ & $x$ & $\checkmark$ & $\checkmark$ & $x$ & $x$ & $\checkmark$ & $x$ \\
\hline Performance Goals & 2 & $x$ & $\mathbf{x} *$ & $\checkmark$ & $\checkmark$ & $\checkmark$ & $x$ & $\checkmark$ & $x$ \\
\hline Injury History & 2 & $x$ & $\checkmark$ & $x$ & $x$ & $x$ & $\checkmark$ & $x$ & $\checkmark$ \\
\hline Injury Likelihood & 2 & $\checkmark$ & $\checkmark$ & $x$ & $x$ & $x$ & $\checkmark$ & $x$ & $\checkmark$ \\
\hline Relatedness & 3 & $\checkmark$ & $\checkmark$ & $\checkmark$ & $\checkmark$ & $x$ & $\checkmark$ & $\checkmark$ & $x$ \\
\hline Competence & 3 & $\checkmark$ & $x$ & $\checkmark$ & $\checkmark$ & $x$ & $x$ & $\checkmark$ & $x$ \\
\hline Autonomy & 3 & $\checkmark$ & $\checkmark$ & $\checkmark$ & $\checkmark$ & $x$ & $\checkmark$ & $\checkmark$ & $x$ \\
\hline Cohesion & 3 & $\checkmark$ & $\checkmark$ & $\checkmark$ & $\checkmark$ & $x$ & $\checkmark$ & $\checkmark$ & $x$ \\
\hline Moral Disengagement & 3 & $\checkmark$ & $\checkmark$ & $x$ & $x$ & $x$ & $\checkmark$ & $x$ & $\checkmark$ \\
\hline Sportspersonship & 3 & $\checkmark$ & $\checkmark$ & $\checkmark$ & $\checkmark$ & $x$ & $\checkmark$ & $\checkmark$ & $x$ \\
\hline Relationship Quality & 3 & $\checkmark$ & $x$ & $\checkmark$ & $\checkmark$ & $x$ & $x$ & $\checkmark$ & $x$ \\
\hline Need Thwarting - Relatedness & 3 & $\checkmark$ & $\checkmark$ & $\checkmark$ & $\checkmark$ & $x$ & $\checkmark$ & $x$ & $x$ \\
\hline Need Thwarting - Competence & 3 & $\checkmark$ & $\checkmark$ & $\checkmark$ & $\checkmark$ & $x$ & $\checkmark$ & $x$ & $\checkmark$ \\
\hline Need Thwarting - Autonomy & 3 & $\checkmark$ & $\checkmark$ & $\checkmark$ & $\checkmark$ & $x$ & $\checkmark$ & $x$ & $\checkmark$ \\
\hline Summary of Support & --- & $23 / 25$ & $15 / 25$ & $20 / 25$ & $20 / 25$ & $1 / 25$ & $15 / 25$ & $16 / 25$ & $8 / 25$ \\
\hline
\end{tabular}

Notes. $\checkmark=$ evidence supported hypothesis. $\mathbf{x}=$ evidence did not support hypothesis. $\mathbf{x} *=$ evidence supported an opposite pattern of differences. H1-H6 corresponds to hypotheses 1 to 6 . < and > values correspond to hypothesised differences in adjustment between passion subtypes (e.g., PHP > POP predicts that PHP is associated with better adjustment than POP). $\mathrm{PHP}=$ pure harmonious passion. $\mathrm{POP}=$ pure obsessive passion. $\mathrm{MP}=$ mixed passion. $\mathrm{NP}=$ nonpassion. 
Figure 1
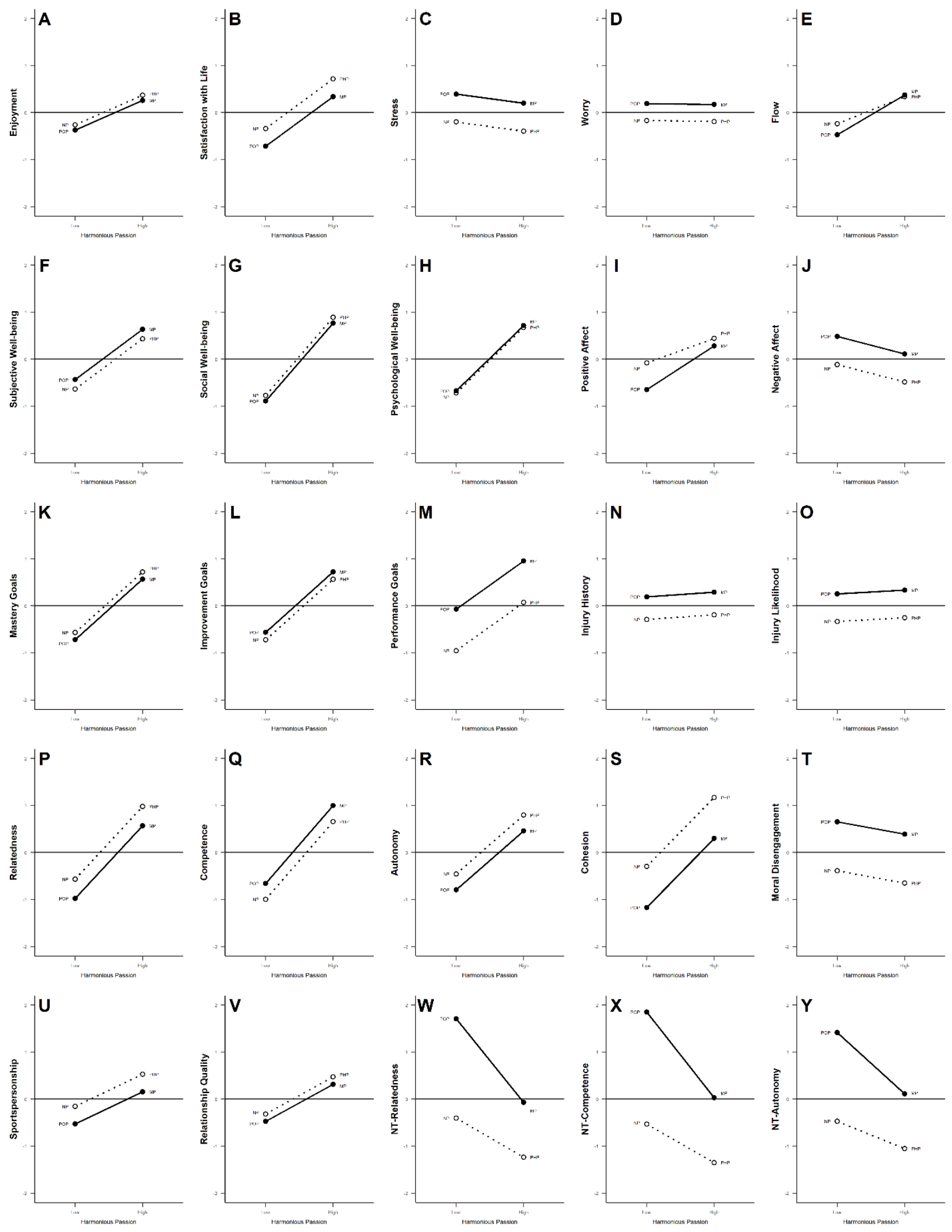


\section{Supplementary Material}

The two dimensions of passion for sport: A new look using a quadripartite approach

\section{Latent Variable Modelling}

Harmonious and obsessive passion (Samples 1, 2, and 3). With each sample, items assessing HP and OP were specified as indicators of HP and OP latent factors. With Samples 1 and 2, these models did not adequately fit the data. With all samples, specifying three sets of correlated residuals substantially improved model fit and resulted in well-fitting models: items 1 with 8,1 with 10 , and 8 with 10 (see Vallerand, 2015 for the complete passion scale and item content). These three sets of correlated residuals were each from HP subscale and have been specified in previous research with the passion scale (e.g., Marsh et al., 2013; Schellenberg et al., 2014; Schellenberg et al., 2019). We therefore interpreted models that included these three correlated residuals in all analyses.

Enjoyment (Sample 1). All items assessing enjoyment were specified to load onto one latent factor. This model yielded acceptable indices of fit.

Satisfaction with life (Sample 1). All items of the SWLS were specified to load onto one latent factor. This model yielded acceptable indices of fit.

Worry (Sample 1). All items assessing worrying were specified to load onto one latent factor. This model yielded acceptable indices of fit.

Flow (Sample 2). All items of the C-FSS were specified to load onto one latent factor. This model yielded acceptable indices of fit. 
Well-being (Sample 2). All items of the Sport MHC-SF were specified to load onto the appropriate latent factor (subjective, psychological, or social well-being). This 3-factor model yielded acceptable indices of fit.

Positive and negative feelings (Sample 2). All items of the SPANE were specified to load onto the appropriate latent factor (positive feelings or negative feelings). This 2-factor model yielded acceptable indices of fit.

Goal attainment (Sample 2). All items of the A-SAGS were specified to load onto the appropriate latent factor (mastery, self-improvement, or performance goals). This 3-factor model yielded acceptable indices of fit.

Injury experiences (Sample 2). Both assessments of injury experiences in sport (past injury history and likelihood of future injury) were modeled as separate observed variables and included in CFAs with HP and OP, and in the CFA with all variables. Injury scores were standardized in order to be consistent with the results from latent factors.

Psychological need satisfaction (Sample 3). In three separate CFAs, latent variables representing relatedness, competence, and autonomy were modeled by specifying individual items to load on a single latent factor. With relatedness and competence, these models fit the data well. With autonomy, acceptable model fit was reached with one correlated residual specified between items 1 and 2 . We therefore interpreted models that included this correlated residual.

Group cohesion (Sample 3). We tested a model in which scores for each GEQ subscale were averaged and included as four parcelled indicators of a latent group cohesion variable. We adopted this approach because we were interested in overall levels of cohesion rather than specific types of group cohesion. This model yielded acceptable indices of fit. 
Moral disengagement (Sample 3). All items of the MDSS-S were specified to load onto one latent factor. This model did not fit the data well. Inspection of item loadings and recommended modification indices led us to exclude two items with very low fit (items 4 and 5) and correlate residuals between two items (items 1 and 2). These modifications yielded acceptable indices of fit, but also require a cautious interpretation of the findings.

Sportspersonship (Sample 3). We tested a model in which scores for each MSOS-25 subscale were averaged and included as four parcelled indicators of a latent sportspersonship variable. We adopted this approach because we were interested in overall levels of sportspersonship rather than specific types of sportspersonship. This model did not yield acceptable indices of fit. Inspection of indicator loadings revealed a very low factor loading for the indicator representing a negative approach toward the practice of sport. Removing this indicator resulted in a model with acceptable fit indices; we therefore interpreted this 3-indicator model.

Teammate relationship quality (Sample 3). All items of the QIRS were specified to load onto one latent factor. This model yielded acceptable indices of fit.

Psychological need thwarting (Sample 3). All items of the PNTS were specified to load onto the appropriate latent factor (autonomy thwarting, competence thwarting, or relatedness thwarting). This 3-factor model yielded acceptable indices of fit. 
Table S1

Sample 1: Descriptive Statistics and Correlations between Latent Variables

\begin{tabular}{lccccccc}
\hline & $M$ & $S D$ & 1 & 2 & 3 & 4 & 5 \\
\hline 1. Harmonious Passion & 4.60 & 1.23 & $(.88)$ & & & & \\
2. Obsessive Passion & 2.61 & 1.37 & $.57^{* *}$ & $(.89)$ & & & \\
3. Enjoyment & 4.51 & 0.65 & $.47^{* *}$ & $.21^{* *}$ & $(.94)$ & & \\
4. Satisfaction with Life & 4.49 & 1.29 & $.34^{* *}$ & .09 & $.19^{* *}$ & $(.91)$ & \\
5. Stress & 26.22 & 21.37 & .07 & $.24^{* *}$ & $-.11^{*}$ & -.06 & --- \\
6. Worry & 2.08 & 0.77 & $.13^{*}$ & $.24^{* *}$ & $.11^{*}$ & -.02 & $.42^{* *}$ \\
\hline
\end{tabular}

Note. $N=442$. Correlations among latent variables were obtained from CFA that included all variables. Composite reliability is presented on the diagonal in parentheses. Means $(M)$ and standard deviations $(S D)$ were calculated in SPSS using observed variables. Note that any items that were excluded as part of the CFA were also excluded from subscale calculations. $* p \leq .05,{ }^{* *} p \leq .01$. 
Table S2

Sample 2: Descriptive Statistics and Correlations between Latent Variables

\begin{tabular}{|c|c|c|c|c|c|c|c|c|c|c|c|c|c|c|c|}
\hline & $M$ & $S D$ & 1 & 2 & 3 & 4 & 5 & 6 & 7 & 8 & 9 & 10 & 11 & 12 & 13 \\
\hline 1. Harmonious Passion & 4.59 & 1.19 & $(.84)$ & & & & & & & & & & & & \\
\hline 2. Obsessive Passion & 2.54 & 1.33 & $.61^{* *}$ & $(.88)$ & & & & & & & & & & & \\
\hline 3. Flow & 3.73 & 0.68 & $.55^{* *}$ & $.32^{* *}$ & $(.93)$ & & & & & & & & & & \\
\hline 4. Subjective WB & 3.34 & 1.05 & $.58^{* *}$ & $.41^{* *}$ & $.61^{* *}$ & $(.90)$ & & & & & & & & & \\
\hline 5. Social WB & 2.96 & 1.27 & $.59^{* *}$ & $.33^{* *}$ & $.56^{* *}$ & $.80^{* *}$ & $(.92)$ & & & & & & & & \\
\hline 6. Psychological WB & 2.98 & 1.21 & $.63^{* *}$ & $.39^{* *}$ & $.63^{* *}$ & $.85^{* *}$ & $.91^{* *}$ & (.93) & & & & & & & \\
\hline 7. Positive Affect & 3.95 & 0.61 & $.44^{* *}$ & $.12^{*}$ & $.65^{* *}$ & $.60^{* *}$ & $.51^{* *}$ & $.52^{* *}$ & $(.86)$ & & & & & & \\
\hline 8. Negative Affect & 1.73 & 0.61 & -.01 & $.28^{* *}$ & $-.26^{* *}$ & $-.29^{* *}$ & $-.19^{* *}$ & $-.21^{* *}$ & $-.53^{* *}$ & $(.84)$ & & & & & \\
\hline 9. Mastery Goals & 4.48 & 1.10 & $.73^{* *}$ & $.38^{* *}$ & $.72 * *$ & $.66^{* *}$ & $.67^{* * *}$ & $.74^{* *}$ & $.57^{* *}$ & $-.20^{* *}$ & $(.82)$ & & & & \\
\hline 10. Improvement Goals & 3.73 & 1.35 & $.57^{* *}$ & $.39^{* *}$ & $.50 * *$ & $.49^{* *}$ & $.55^{* *}$ & $.58^{* *}$ & $.39^{* *}$ & -.10 & $.81 * *$ & $(.92)$ & & & \\
\hline 11. Performance Goals & 3.08 & 1.51 & $.55^{* *}$ & $.53^{* *}$ & $.47 * *$ & $.48^{* *}$ & $.52^{* *}$ & $.56^{* *}$ & $.25^{* *}$ & .03 & $.74 * *$ & $.77 * *$ & (.93) & & \\
\hline 12. Injury History & 0.85 & 1.34 & $.19^{* *}$ & $.27^{* *}$ & $.14 * *$ & $.11^{* *}$ & $.13^{* *}$ & $.15^{* *}$ & .05 & $.09^{*}$ & $.16^{* *}$ & $.12 * *$ & $.18 * *$ & --- & \\
\hline 13. Injury Likelihood & 2.82 & 1.76 & $.22^{* *}$ & $.32^{* *}$ & $.17 * *$ & $.12^{* *}$ & $.17^{* *}$ & $.18^{* *}$ & .03 & $.22^{* *}$ & $.21 * *$ & $.14 * *$ & $.20 * *$ & $.57 * *$ & --- \\
\hline
\end{tabular}

Note. $N=499$. Correlations among latent variables were obtained from CFA that included all variables. Composite reliability is presented on the diagonal in parentheses. Means $(M)$ and standard deviations $(S D)$ were calculated in SPSS using observed variables. WB $=$ well-being $* p \leq$ $.05, * * p \leq .01$. 
Table S3

Sample 3: Descriptive Statistics and Correlations between Latent Variables

\begin{tabular}{|c|c|c|c|c|c|c|c|c|c|c|c|c|c|c|}
\hline & $M$ & $S D$ & 1 & 2 & 3 & 4 & 5 & 6 & 7 & 8 & 9 & 10 & 11 & 12 \\
\hline 1. Harmonious Passion & 4.37 & 1.23 & $(.88)$ & & & & & & & & & & & \\
\hline 2. Obsessive Passion & 2.48 & 1.31 & $.63^{* *}$ & $(.88)$ & & & & & & & & & & \\
\hline 3. Relatedness & 5.25 & 1.19 & $.57^{* *}$ & $.25^{* *}$ & $(.93)$ & & & & & & & & & \\
\hline 4. Competence & 4.40 & 1.32 & $.71^{* *}$ & $.52^{* *}$ & $.57^{* *}$ & $(.94)$ & & & & & & & & \\
\hline 5. Autonomy & 5.12 & 1.13 & $.51^{* *}$ & $.23^{* *}$ & $.46^{* *}$ & $.45^{* *}$ & $(.87)$ & & & & & & & \\
\hline 6. Cohesion & 6.48 & 1.22 & $.42^{* *}$ & .03 & $.75^{* *}$ & $.38^{* *}$ & $.28^{* *}$ & $(.86)$ & & & & & & \\
\hline 7. Moral Disengagement & 2.64 & 1.26 & $.21^{* *}$ & $.44^{* *}$ & .05 & $.50^{* *}$ & $.39^{* *}$ & -.08 & $(.85)$ & & & & & \\
\hline 8. Sportspersonship & 3.89 & 0.54 & $.37^{* *}$ & .06 & $.49^{* *}$ & $-.15^{* *}$ & $-.24^{* *}$ & $.44^{* *}$ & $-.28^{* *}$ & $(.78)$ & & & & \\
\hline 9. Relationship Quality & 2.79 & 0.82 & $.56^{* *}$ & $.28^{* *}$ & $.85^{* *}$ & -.11 & $-.20^{* *}$ & $.75^{* *}$ & .05 & $.46^{* *}$ & $(.90)$ & & & \\
\hline 10. NT - Relatedness & 2.17 & 1.18 & -.09 & $.31^{* *}$ & $-.40^{* *}$ & -.02 & $-.35^{* *}$ & $-.58^{* *}$ & $.24^{* *}$ & $-.30^{* *}$ & $-.40^{* *}$ & $(.88)$ & & \\
\hline 11. NT-Competence & 2.50 & 1.33 & -.02 & $.37^{* *}$ & $-.26^{* *}$ & $.22^{* *}$ & -.01 & $-.46^{* *}$ & $.30^{* *}$ & $-.30^{* *}$ & $-.23^{* *}$ & $.80^{* *}$ & $(.92)$ & \\
\hline 12. NT - Autonomy & 2.79 & 1.38 & .04 & $.36^{* *}$ & $-.20^{* *}$ & $.30^{* *}$ & $.40^{* *}$ & $-.39^{* *}$ & $.33^{* *}$ & $-.30^{* *}$ & $-.19^{* *}$ & $.61^{* *}$ & $.72^{* *}$ & $(.89)$ \\
\hline
\end{tabular}

Note. $N=349$. Correlations among latent variables were obtained from CFA that included all variables. Composite reliability is presented on the diagonal in parentheses. Means $(M)$ and standard deviations $(S D)$ were calculated in SPSS using observed variables. Note that any items that were excluded as part of the CFA were also excluded from subscale calculations. NT $=$ Need Thwarting. $* p \leq .05, * * p \leq .01$. 
Table S4

Sample 1: Confirmatory Factor Analyses

\begin{tabular}{|c|c|c|c|c|c|c|c|}
\hline \multirow[t]{2}{*}{ Model Description } & \multicolumn{3}{|c|}{$\chi^{2}$} & \multicolumn{2}{|c|}{ RMSEA } & \multirow[t]{2}{*}{ CFI } & \multirow[t]{2}{*}{ TLI } \\
\hline & Value & $d f$ & $p$ & Value & $90 \% \mathrm{CI}$ & & \\
\hline Passion (2 factor) & 342.455 & 53 & $<.001$ & .111 & {$[.100, .123]$} & .890 & .862 \\
\hline Passion (2 factor with CRs) & 176.272 & 50 & $<.001$ & .076 & {$[.064, .088]$} & .952 & .936 \\
\hline Enjoyment & 4.038 & 2 & .133 & .048 & {$[.000, .117]$} & .997 & .990 \\
\hline Satisfaction with Life & 8.556 & 5 & .128 & .040 & {$[.000, .085]$} & .996 & .992 \\
\hline Worry & 10.632 & 5 & .059 & .050 & {$[.000, .093]$} & .994 & .989 \\
\hline Passion (2 factor with CRs) + Enjoyment & 280.921 & 98 & $<.001$ & .065 & {$[.056, .074]$} & .955 & .945 \\
\hline Passion (2 factor with CRs) + Satisfaction with Life & 274.062 & 113 & $<.001$ & .057 & {$[.048, .065]$} & .960 & .951 \\
\hline Passion (2 factor with CRs) + Stress & 194.619 & 60 & $<.001$ & .071 & {$[.060, .083]$} & .950 & .935 \\
\hline Passion (2 factor with CRs) + Worry & 283.924 & 113 & $<.001$ & .058 & {$[.050, .067]$} & .958 & .950 \\
\hline All Variables & 566.857 & 307 & $<.001$ & .044 & {$[.038, .049]$} & .963 & .958 \\
\hline
\end{tabular}

Note. CRs: P1 w P8, P1 w P10, P8 w P10 
Table S5

Sample 2: Confirmatory Factor Analyses

\begin{tabular}{|c|c|c|c|c|c|c|c|}
\hline \multirow[t]{2}{*}{ Model Description } & \multicolumn{3}{|c|}{$\chi^{2}$} & \multicolumn{2}{|c|}{ RMSEA } & \multirow[t]{2}{*}{ CFI } & \multirow[t]{2}{*}{ TLI } \\
\hline & Value & $d f$ & $p$ & Value & $90 \% \mathrm{CI}$ & & \\
\hline Passion (2 factor) & 440.893 & 53 & $<.001$ & .121 & {$[.111, .132]$} & .836 & .796 \\
\hline Passion (2 factor with CRs) & 160.174 & 50 & $<.001$ & .066 & {$[.055, .078]$} & .953 & .939 \\
\hline Flow & 84.896 & 35 & $<.001$ & .053 & {$[.039, .068]$} & .975 & .968 \\
\hline SMHC (3 factor) & 330.689 & 74 & $<.001$ & .083 & {$[.074, .093]$} & .938 & .924 \\
\hline Affect (2 factor) & 144.081 & 53 & $<.001$ & .059 & {$[.047, .070]$} & .951 & .940 \\
\hline Goals (3 factor) & 282.174 & 51 & $<.001$ & .095 & {$[.085, .106]$} & .933 & .913 \\
\hline Passion (2 factor with CRs) + Flow & 493.226 & 203 & $<.001$ & .054 & {$[.048, .060]$} & .944 & .936 \\
\hline Passion (2 factor with CRs) + SMHC (3 factor) & 807.546 & 286 & $<.001$ & .060 & {$[.056, .065]$} & .933 & .924 \\
\hline Passion (2 factor with CRs) + Affect (2 factor) & 534.591 & 243 & $<.001$ & .049 & {$[.043, .055]$} & .941 & .932 \\
\hline Passion (2 factor with CRs) + Goals (3 factor) & 680.270 & 239 & $<.001$ & .061 & {$[.055, .066]$} & .935 & .924 \\
\hline Passion (2 factor with CRs) + Injury History & 174.520 & 60 & $<.001$ & .062 & {$[.051, .073]$} & .953 & .939 \\
\hline Passion (2 factor with CRs) + Injury Likelihood & 187.157 & 60 & $<.001$ & .065 & {$[.055, .076]$} & .949 & .934 \\
\hline All Variables & 3297.089 & 1750 & $<.001$ & .042 & {$[.040, .044]$} & .919 & .912 \\
\hline
\end{tabular}

Note. CRs: P1 w P8, P1 w P10, P8 w P10. SMHC = Sport Mental Health Continuum 
Table S6

Sample 3: Confirmatory Factor Analyses

\begin{tabular}{|c|c|c|c|c|c|c|c|}
\hline \multirow[t]{2}{*}{ Model Description } & \multicolumn{3}{|c|}{$\chi^{2}$} & \multicolumn{2}{|c|}{ RMSEA } & \multirow[t]{2}{*}{ CFI } & \multirow[t]{2}{*}{ TLI } \\
\hline & Value & $d f$ & $p$ & Value & $90 \% \mathrm{CI}$ & & \\
\hline Passion (2 factor) & 143.853 & 53 & $<.001$ & .070 & {$[.056, .084]$} & .943 & .928 \\
\hline Passion (2 factor with CRs) & 102.804 & 50 & $<.001$ & .055 & {$[.040, .070]$} & .967 & .956 \\
\hline Relatedness & 10.454 & 5 & .063 & .056 & {$[.000, .104]$} & .992 & .985 \\
\hline Competence & 34.459 & 5 & $<.001$ & .130 & {$[.091, .173]$} & .972 & .944 \\
\hline Autonomy & 101.962 & 5 & $<.001$ & .236 & {$[.197, .277]$} & .831 & .662 \\
\hline Autonomy (with CR) & 3.324 & 4 & .505 & .000 & {$[.000, .074]$} & 1.00 & 1.00 \\
\hline Cohesion (4 parcelled indicators) & 2.542 & 2 & .281 & .028 & {$[.000, .114]$} & .999 & .996 \\
\hline Moral Disengagement & 206.650 & 20 & $<.001$ & .164 & {$[.144, .184]$} & .745 & .643 \\
\hline Moral Disengagement (6 items with CR) & 25.016 & 8 & .001 & .078 & {$[.045, .114]$} & .970 & .944 \\
\hline Sportspersonship (4 parcelled indicators) & 30.511 & 5 & $<.001$ & .121 & {$[.082, .164]$} & .915 & .830 \\
\hline Sportspersonship (3 parcelled indicators) & 3.110 & 2 & .211 & .040 & {$[.000, .121]$} & .995 & .986 \\
\hline Relationship Quality & 0.043 & 2 & .979 & .000 & {$[.000, .000]$} & 1.00 & 1.00 \\
\hline Need Thwarting (3 factor) & 125.160 & 51 & $<.001$ & .065 & {$[.050, .079]$} & .961 & .949 \\
\hline Passion (2 factor with CRs) + Relatedness & 210.641 & 113 & $<.001$ & .050 & {$[.039, .060]$} & .966 & .959 \\
\hline Passion (2 factor with CRs) + Competence & 236.094 & 113 & $<.001$ & .056 & {$[.046, .066]$} & .962 & .954 \\
\hline Passion (2 factor with CRs) + Autonomy (with CR) & 212.656 & 112 & $<.001$ & .051 & {$[.040, .061]$} & .961 & .953 \\
\hline Passion ( 2 factor with CRs) + Cohesion & 205.900 & 98 & $<.001$ & .056 & {$[.045, .067]$} & .953 & .943 \\
\hline Passion ( 2 factor with CRs) + Moral Disengagement (6 items with CR) & 255.150 & 128 & $<.001$ & .053 & {$[.044, .063]$} & .949 & .939 \\
\hline Passion ( 2 factor with CRs) + Sportspersonship (3 parcelled indicators) & 242.477 & 98 & $<.001$ & .065 & {$[.055, .075]$} & .933 & 917 \\
\hline Passion (2 factor with CRs) + Relationship Quality & 191.599 & 98 & $<.001$ & .052 & {$[.041, .063]$} & .963 & .955 \\
\hline Passion ( 2 factor with CRs) + Need Thwarting ( 3 factor) & 425.056 & 239 & $<.001$ & .047 & {$[.040, .054]$} & .955 & .948 \\
\hline All Variables & 2440.292 & 1468 & $<.001$ & .044 & {$[.040, .047]$} & .923 & .917 \\
\hline
\end{tabular}

Note. $N=349$. Passion correlated residuals (CRs): P1 w P8, P1 w P10, P8 w P10. Autonomy CR: item 1 with 2. Moral

Disengagement CR: item 4 and 5. 


\section{Figure S1}

Scatterplot of the relationship between harmonious passion and obsessive passion for each sample

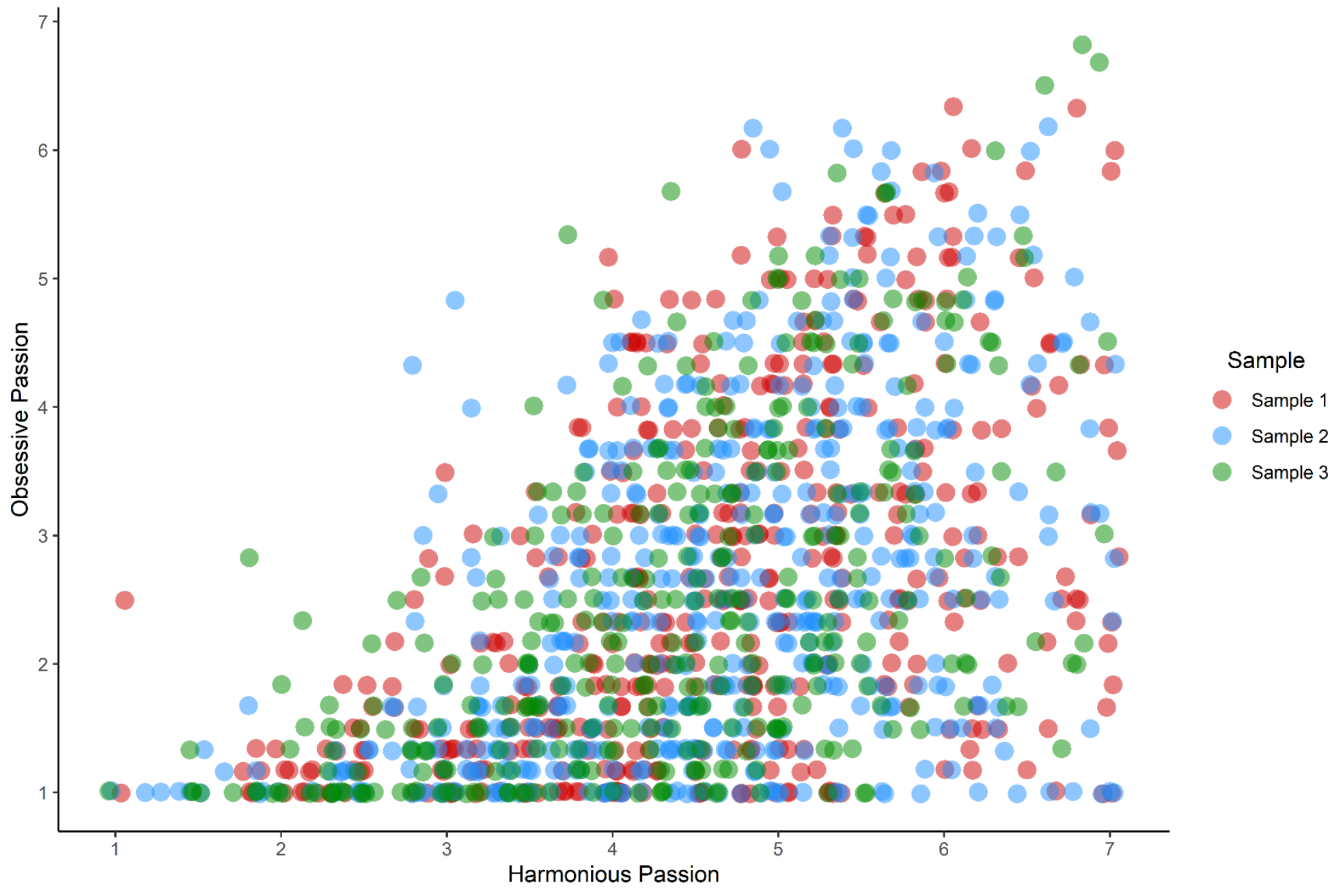

Note. Mean scores are reported. Jittered points are displayed to avoid overplotting. 


\section{Moderation Effect of Gender}

We tested if any of the main and interactive effects reported in the main analysis (see Table 1 in the main text) depended on gender. This was treated as an exploratory analysis because gender effects with passion are rarely reported and were therefore not hypothesized. Participants who either did not report a gender or who identified as non-binary were not included in these analyses. We found a significant interaction between obsessive passion and gender when predicting moral disengagement in Sample 3, $b=0.420, S E=0.155,95 \%$ CI $[0.115,0.724], p=$ .007. Simple slopes revealed that OP was positively associated with moral disengagement among males, $b=0.536, S E=0.118,95 \%$ CI [0.305, 0.766], $p<.001$. This effect, however, was not significant among females, $b=0.116, S E=0.115,95 \%$ CI $[-0.110,0.342], p=.315$. Gender did not moderate any of the other effects that we observed in the main analysis.

Passion subtype comparisons with moral disengagement for male and female participants are displayed in Table S7. A plot of predicted values is displayed in Figure S2. The subtype differences observed in the main analyses appear with male participants, and not female participants. Given that gender effects were not hypothesized or found with any of the other outcomes in this research, we believe additional research is needed before drawing any conclusions. 
Table S7

Association Between Passion Subtypes and Moral Disengagement for Females and Males

\begin{tabular}{|c|c|c|c|c|c|}
\hline Outcome Variable & $d$ & Description & $B$ & $S E$ & $95 \% \mathrm{CI}$ \\
\hline \multicolumn{6}{|l|}{ Females } \\
\hline H1: PHP v. POP & -0.385 & ----- & ----- & ----- & ----- \\
\hline H2: MP v. PHP & 0.273 & OP main effect & 0.116 & 0.115 & {$[-0.110,0.342]$} \\
\hline H3: PHP v. NP & -0.112 & HP main effect & -0.070 & 0.112 & {$[-0.290,0.151]$} \\
\hline H4: MP v. POP & -0.112 & HP main effect & -0.070 & 0.112 & {$[-0.290,0.151]$} \\
\hline H5: POP v. NP & 0.273 & OP main effect & 0.116 & 0.115 & {$[-0.110,0.342]$} \\
\hline H6: MP v. NP & 0.161 & ---- & ----- & ----- & --- \\
\hline \multicolumn{6}{|l|}{ Males } \\
\hline H1: PHP v. POP & $-1.593 * *$ & ----- & ----- & ----- & ----- \\
\hline H2: MP v. PHP & $1.260 * *$ & OP main effect & $0.536 * *$ & 0.118 & {$[0.305,0.766]$} \\
\hline H3: PHP v. NP & -0.333 & HP main effect & -0.207 & 0.157 & {$[-0.514,0.100]$} \\
\hline H4: MP v. POP & -0.333 & HP main effect & -0.207 & 0.157 & {$[-0.514,0.100]$} \\
\hline H5: POP v. NP & $1.260 * *$ & OP main effect & $0.536^{* *}$ & 0.118 & {$[0.305,0.766]$} \\
\hline H6: MP v. NP & $0.927 * *$ & ----- & ----- & ----- & ---- \\
\hline
\end{tabular}

Note. H1-H6 corresponds to hypotheses 1 to 6 . Unstandardized beta coefficients are reported. $\mathrm{PHP}=$ pure harmonious passion. $\mathrm{POP}=$ pure obsessive passion. $\mathrm{MP}=$ mixed passion. $\mathrm{NP}=$ non-passion. $\mathrm{HP}=$ harmonious passion. $\mathrm{OP}=$ obsessive passion. $* p \leq .05 . * * p \leq .01$ 


\section{Figure S2}

Associations between harmonious passion, obsessive passion, and moral disengagement among female and male participants.
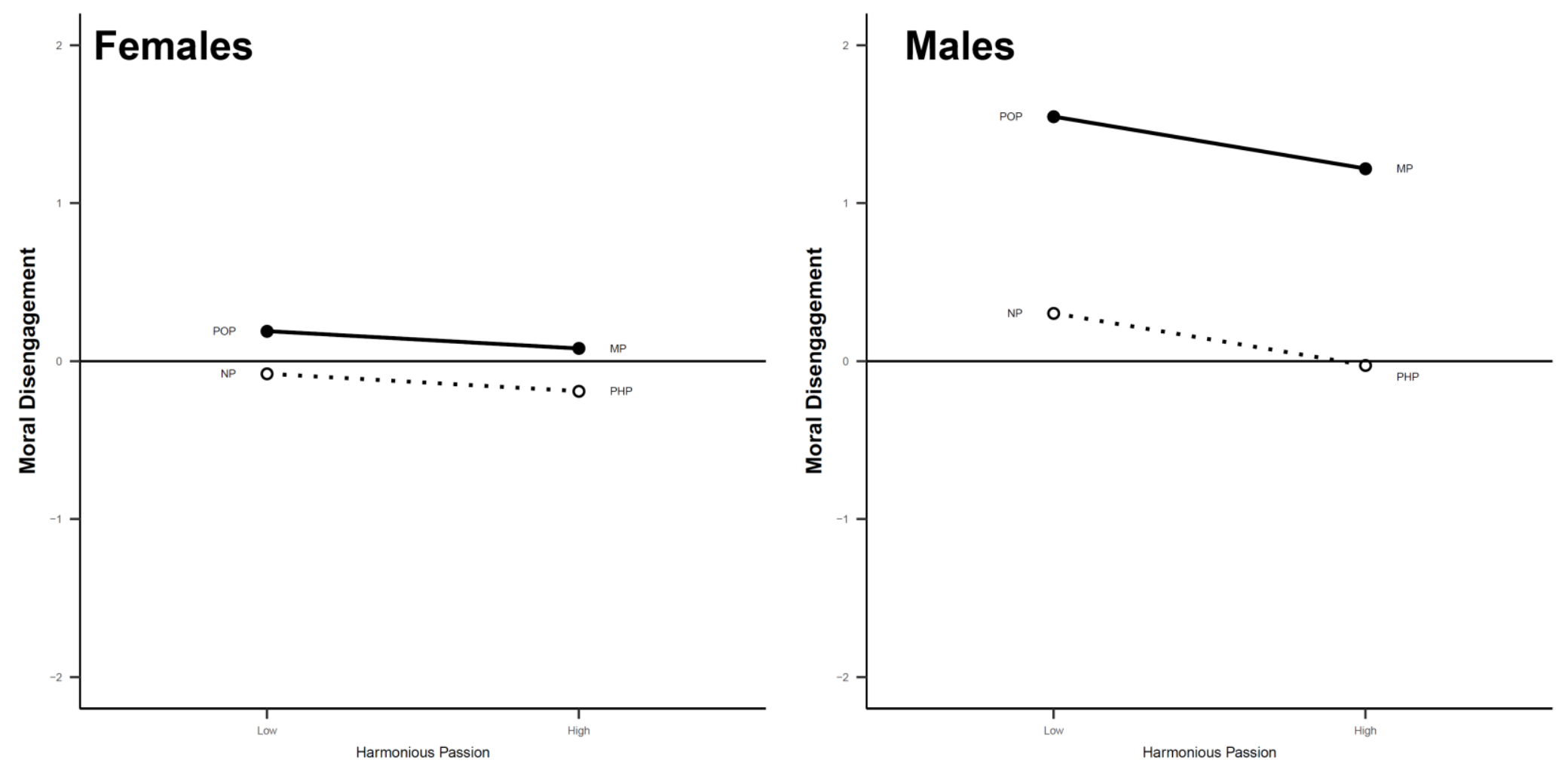

Note. High and low values of harmonious and obsessive passion are plotted at one standard deviation above and below the mean. Solid lines represent high obsessive passion; dotted lines represent low obsessive passion. Passion scores are mean centered and all outcomes are standardized. $\mathrm{PHP}=$ pure harmonious passion; $\mathrm{POP}=$ pure obsessive passion; $\mathrm{MP}=$ mixed passion; $\mathrm{NP}=$ non passion . 